\title{
An in-the-wild study of learning to brainstorm: comparing cards, tabletops and wall displays in the classroom
}

\author{
Andrew Clayphan', Roberto Martinez-Maldonado', Martin Tomitsch', \\ Susan Atkinson ${ }^{3}$, Judy Kay ${ }^{1}$ \\ ${ }^{1}$ School of Information Technologies, The University of Sydney 2006, Australia \\ ${ }^{2}$ Faculty of Architecture, Design and Planning, The University of Sydney 2006, Australia \\ ${ }^{3}$ Sydney eLearning, The University of Sydney 2006, Australia \\ andrew.clayphan@sydney.edu.au,roberto@it.usyd.edu.au, martin.tomitsch@sydney.edu.au, \\ susan.atkinson@sydney.edu.au, judy.kay@sydney.edu.au
}

\begin{abstract}
Single display interactive groupware interfaces have the potential to effectively support smallgroup work in classrooms. Our work aimed to gain understanding needed to realise that potential. First, we wanted to study how learners use these large interactive displays, compared with a more traditional method within classrooms. Second, we wanted to fill gaps in the current understanding of the effectiveness of interactive tables versus walls. Third, we wanted to do this out of the laboratory setting, in authentic classrooms, with their associated constraints. We conducted an in-the-wild study, with 51 design students, working in 14 groups, learning the brainstorming technique. Each group practiced brainstorming in three classrooms: one with vertical displays (walls); another with multi-touch tabletops; and the third with pens and index cards. The published literature suggested that tabletops would be better than the other conditions for key factors of cooperative participation, mutual awareness, maintaining interest and affective measures. Contrary to this, we found that the horizontal and vertical displays both had similar levels of benefit over the conventional method. It was only for affective measures that tabletops were better than walls. All conditions were similar for our several measures of outcome quality. We discuss the implications of our findings for designing future classrooms.
\end{abstract}

Keywords

Interactive tabletops; Collocated collaboration; Creativity; Interactive vertical displays; Single display groupware; Brainstorming; Studies in the wild

Research Highlights

- An in-the-wild study of single-display groupware (SDG) for students learning to brainstorm, a richly collaborative activity involving a divergent ideation phase and convergent discussion and idea selection phases.

- Both SDGs had benefits over the conventional method (which used pens and index cards).

- Comparing interactive tabletops with vertical displays, students preferred tabletops, but measures of brainstorming results and collaboration were similar.

\section{Introduction and Motivation}

Large display interactive groupware is becoming increasingly more affordable, making it possible to create classrooms with interactive surfaces on tables and walls. Although, there are possible benefits and latent risks in introducing new technologies in learning settings (Muir-Herzig, 2004), interactive surfaces have the potential to effectively support small-group work and collaboration (Evans and Rick, 2014). This is important because it has been demonstrated that small group learning can activate valuable learning mechanisms (Chen, 2006; Deutsch, 1949; Dillenbourg, 1999; Johnson and Johnson, 1987; Koschmann, 1996). This is reflected in the common practice of group work in classrooms from K- 

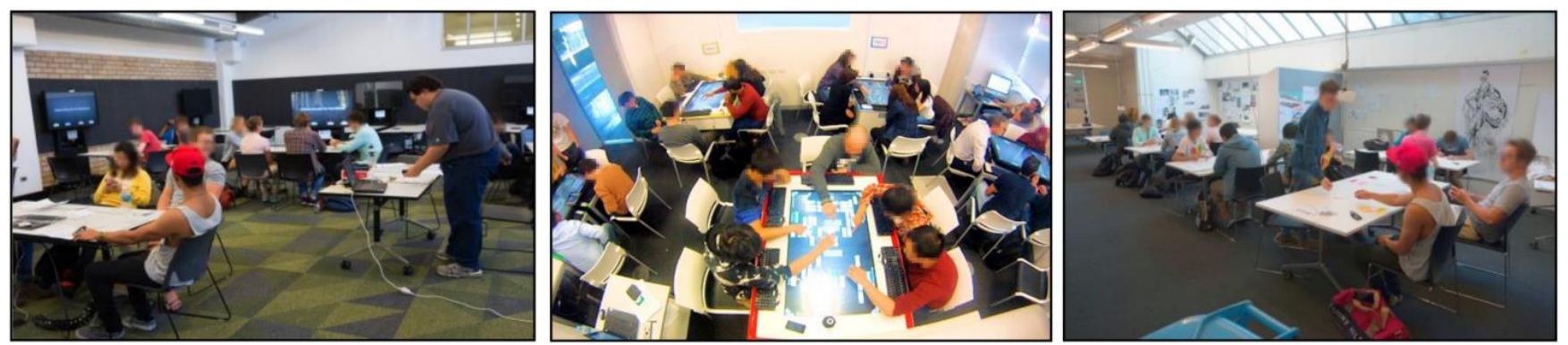

Figure 1: Our three authentic classroom designs. Left: Interactive vertical displays. Centre: Multiple interactive-tabletops. Right: Regular tables for paper-based activities.

12, to the tertiary level and beyond (Barkley et al., 2014; Gillies, 2003; Springer et al., 1999). Another important aspect follows from the important role of group work in diverse settings (Kozlowski and Bell, 2003; Kozlowski and Ilgen, 2006), with teams "the strategy of choice when organizations are confronted with complex and difficult tasks" (Salas et al., 2008). This second aspect has had important educational implications, with the ability to work in a group being recognised as an important generic skill to build into the curriculum (Binkley et al., 2012; Darling-Hammond, 2012; OECD, 2011, 2013). Broadly, emerging technology has the potential to play an important role in classrooms (Salter et al., 2013; Slotta, 2010), both in helping students learn the subject matter and develop collaboration skills more effectively, by opening new channels of interaction with content and their peers (Stahl et al., 2006).

We aim to contribute understanding to the different ways that emergent single-display groupware (SDG) may potentially support collaboration and group work, particularly in classrooms. Our study is based on learning to brainstorm (Osborn, 1953; Paulus, 2000), an established method of group ideation. It makes for an interesting case study because it is widely used, is part of the University of Sydney's design students' standard curriculum and involves widely-used types of collaborative activities. It starts with freewheeling divergent idea generation where group members call out their ideas and the ideas of each group member typically spark more ideas by others in the group. This is followed by convergent phases where the group reviews the ideas, organising and discussing them to identify the most promising ones. Our work aims to enhance our understanding of the ways that interactive tabletop and wall technology can support such activities.

Our study made use of three classrooms available at our university. Figure 1 (left) shows one of the large collaborative learning spaces with a vertical display for each group. We wanted to gain understanding of its benefits over a conventional studio classroom without digital technology, such as the one we used in the study, shown at the right of the figure. In addition, we wanted to compare both of these with a tabletop classroom, like ours shown at the centre of the figure. Our research questions were:

1. Do SDGs provide benefits over conventional card-based methods for students learning to brainstorm?

2. Do tabletops provide better support for students learning to brainstorm in terms of the nature of the collaboration (both observed and perceived) and in the quality of the brainstorm outcomes?

Current research gives no clear answers, even from lab studies, much less from real-world classrooms, with all the associated curriculum and timing constraints of an actual university class.

Interactive vertical displays are already very widely deployed and used in first-world classrooms, from elementary to university levels (Shi et al., 2012). There has been considerable research into the use and 
effectiveness of these vertical displays (Higgins et al., 2007; Sweeney, 2010). Their use and associated research are almost exclusively for whole-class activities (Betcher and Leicester, 2009; Smith et al., 2005), rather than for small group work (Evans and Rick, 2014; Higgins et al., 2007). Our first research question is important for the already emerging SDG-enhanced classrooms like the one depicted in Figure 1 (left).

Interactive tabletops are much newer to classroom use (Dillenbourg and Evans, 2011). They have very recently been deployed to a few classrooms for small-group activities (AlAgha et al., 2010; Do-Lenh, 2012; Kharrufa et al., 2013a; Martinez-Maldonado et al., 2012a). But little is known about their effectiveness compared to interactive whiteboards or conventional classrooms for small-group work. Because tabletops are horizontal, they seem to offer benefits over vertical displays for small group work. This is because learners can more easily interact with digital content while maintaining mutual awareness and more natural face-to-face communication, both verbal and non-verbal (Betcher and Leicester, 2009; Müller-Tomfelde and Fjeld, 2012; Potvin et al., 2012). Our second research question explores this potential benefit of tabletops over vertical displays.

The next section reviews previous work on classroom use of both interactive whiteboards and tabletops and on studies that compared horizontal and vertical displays. We then describe the design of our study, which drew upon logs, observations and questionnaires to gain insights about collaboration in terms of the number of ideas generated, participation strategies, mutual awareness, interest, learning space configuration, and the quality of the creativity production. Then we report the results and conclude with a discussion of the implications of our work for designing in-class collaborative activities.

\section{Related Work}

There is a wealth of existing research based on the concept of one interactive whiteboard per classroom. The use of an interactive whiteboard in this context, has been examined in terms of: impact on pedagogies and learning practices (Sweeney, 2010); teaching strategies (Higgins et al., 2007); learning discourse (Murcia and Sheffield, 2010); student perception (Yañez and Coyle, 2011); and student engagement (Hall and Higgins, 2005).

Tabletops have much less research in the classroom. However, research has given rise to guidelines for creating effective systems for co-located collaborative work (Scott et al., 2003), exploration of social dynamics (Morris, 2006), use in educational settings (Dillenbourg and Evans, 2011), and importantly, how they can support collaborative learning (Rick et al., 2011).

For both groupware devices, there have been few studies that explore the use-case of "multiple devices" supporting many groups within the same classroom, much less a comparison of these. We thus explore literature about two aspects: the use of these groupware devices in the classroom; and the studies that have compared orientation effects. Our aim is to better understand the affordances and limitations of each, and what this means for small groups in classroom environment contexts.

\section{Interactive Vertical Displays and Tabletops in the Classroom}

There is widespread deployment of single interactive whiteboards in classrooms, and researchers are divided on the value of their use (Higgins et al., 2007; Smith et al., 2005), particular as they have been used for entire class activities (Evans and Rick, 2014), rather than for small groups. Only recently have we started to see proposals for the use of whiteboards for small group work (Mercer et al., 2010). We are 
also starting to see learning environments with multiple interactive whiteboards (Stockert et al., 2012), which raise questions on how best to support small group processes.

Tabletops are another form of groupware technology. Scott et al. (2003) proposed a number of guidelines for the use of single-tabletop applications, identifying affordances for the use of shared objects, physical user arrangement, and the possibility of leveraging learners' digital traces. However, there have been very few studies of interactive multi-tabletops for class groups (Hatch et al., 2009; AlAgha et al., 2010; Mercier et al., 2012; Martinez-Maldonado et al., 2012a; Kharrufa et al., 2013a). To show how our work relates to those studies, Table 1 overviews their key characteristics. The studies ranged across primary, secondary and tertiary levels of education. Class sizes were from 12-20 students, predominately with 3-4 students per table. The last three columns relate to classroom management. Orchestration tools enable the teacher tools to control aspects such as: freezing the tables (so students attend to whole class activities), moving the application to its next stage, sending messages to the tables (such as a warning of the approaching end of an activity); and sharing the content of one table at a wall display for all students to see (for class discussion and reflection). Awareness tools provide teachers with an overview of the state of each table; which is useful because it may be difficult for a teacher to easily see all the tables. For our study, each teacher used an orchestration tool for both SDGs to progress students through the tutorial and main activity.

Piper and Hollan (2009) and Piper et al. (2012) report on one early study, to explore tabletops for college level students working in pairs. The researchers examined if tabletops had pedagogical value, and if there were effects on cognitive and social behaviour, for people using such devices. The activity was exam revision, over multiple weeks. The input was touch (user-differentiated). The setup consisted of a single tabletop. Students sat side-by-side. The tabletop allowed efficient handling of materials, provided a quick interface to find elements, and supported written annotations. This encouraged students to attempt more problems on their own before looking at answer keys, compared with pencils and paper. The authors report that tabletops alone do not enhance student's learning, and more studies are required to understand how tabletop displays and other digital technology can best fit with and augment existing educational ecologies. This is congruent with other findings in literature, such as Kharrufa et al. (2013b) who proposed how to extend single tabletop designs to multiple table classrooms.

We now review the small number of research projects that have studied classrooms with multiple tabletops to accommodate a whole class working in small groups, each at their own tabletop. One of the first and most relevant projects is SynergyNet (Hatch et al., 2009; AlAgha et al., 2010; Higgins et al., 2012; Mercier et al., 2012; Mercier and Higgins, 2013). This had four multi-touch tabletops in a

\begin{tabular}{|c|c|c|c|c|c|c|}
\hline Study & Context & \# Tables & $\begin{array}{l}\text { Students } \\
\text { per table }\end{array}$ & $\begin{array}{l}\text { Orchestration } \\
\text { tools }\end{array}$ & $\begin{array}{l}\text { Awareness } \\
\text { tools }\end{array}$ & $\begin{array}{l}\text { Central display } \\
\text { (for sharing) }\end{array}$ \\
\hline $\begin{array}{c}\text { SynergyNet } \\
\text { AlAgha et al. (2010) }\end{array}$ & Primary & 4 & 3 & $\checkmark$ & $\checkmark$ & $\checkmark$ \\
\hline $\begin{array}{l}\text { MTClassroom } \\
\text { Martinez-Maldonado et al. (2012a) }\end{array}$ & Tertiary & 4 & $4-6$ & $\checkmark$ & $\checkmark$ & $\checkmark$ \\
\hline $\begin{array}{l}\text { Tables in the wild } \\
\text { Kharrufa et al. (2013a) }\end{array}$ & Secondary & $6-7$ & $2-4$ & $x$ & $x$ & $x$ \\
\hline Our work & Tertiary & 5 & $3-4$ & $\checkmark$ & $x$ & $\mathbf{x} *$ \\
\hline
\end{tabular}

Table 1: Summary of interactive tabletop classroom setups. (Note: Our tabletop classroom did have a central wall display, but this was not used, as the teacher opted to conduct a reflection session at the end of the day, in a separate lecture hall). 
classroom setting, used for experiments with elementary school students in extracurricular problem solving activities, such as answering mysteries based on textual clues; or tasks designed to enhance mathematical fluency. The classroom design also featured a non-interactive vertical display, so the teacher could send the content of an individual table, to be shared with the rest of the class, to support discussion. The teacher was given a dedicated control table, to visualise, interact with and manipulate each group's tabletop. The research involved studies of video-recordings to assess how tabletops supported collaborative interactions and the ways the teacher used the system (Mercier et al., 2012). Notably, this was a laboratory setting, with the students working on tasks outside their regular curriculum and the teacher not involved in the activity design. Overall the results pointed to the tabletops being effective in allowing groups to come to consensus quickly; and the teacher console, useful for orchestrating and monitoring the class.

MTClassroom (Martinez-Maldonado et al., 2012a), was the first in-the-wild study that involved a multitouch tabletop classroom - with 140 tertiary students in their normal tutorial class (8 tutorial slots) with the class activity determined by the curriculum. It featured individual user touch differentiation, enabling detailed learner activity capture. Core to the work was support for classroom orchestration. Five tabletops were linked to a private portable teacher's dashboard. This is similar to SynergyNet, but the control device was portable. The dashboard had two roles: activity control: start, stop, pause, and share to a central (wall) display; and real time tracking and feedback of the progress of each group. The research showed that curated information about each group helped give the teacher awareness of the progress of the whole class and facilitated managing the class, and that the data captured can be used to assess activity designs.

Tables in the wild (Kharrufa et al., 2013a), is important work because it involved an "in-the-wild" study of a series of classes with whole class groups in a primary school over 6 weeks. Students worked in groups of 2-4 at seven small tables in up to 7 sessions. Researchers observed student behaviour and teacher interaction. The teachers reported problems due to the independent operation of the tabletops, with no support to easily see the progress of each group, unlike SynergyNet and MTClassroom. This study led to recommendations for designing multi-tabletop settings deployed in the classroom (Kharrufa et al., 2013b). The distinguishing aspects of this study were its scale and that it was conducted with class groups in a school as part of their formal curriculum.

In summary, there is a considerable body of work on interactive whiteboards for entire class use. However, we are just beginning to see the first research into the classroom use of either tabletops or interactive whiteboards for small group activities. This has motivated our first research question, to consider how SDGs can support small group learning in classroom settings, comparing them against a conventional classroom's group learning activity.

\section{Comparing Horizontal and Vertical Displays}

This section positions our second research question, comparing horizontal and vertical interfaces for collaboration. Table 2 shows a high-level summary in terms of seven key aspects (input, task, multiple orientation design, posture, group size and experimental setup). We aim to gain insights into the current technology in interactive displays, where both horizontal and vertical displays (Col 2) are digital, with multi-touch support (Col 3). We consider it important to study their use for tasks that are rich enough to provide valuable insights into interesting classes of collaboration ( $\mathrm{Col} 4)$. Column 5 shows whether the interface was designed for multiple orientations. This is important if tabletops are to tap their potential for face-to-face interaction. People normally choose to sit facing each other around a table (as one can readily observe in any coffee shop or restaurant). In classroom settings, where it is common to have 


\begin{tabular}{|c|c|c|c|c|c|c|c|}
\hline Study & $\begin{array}{c}\text { Digital (D) or } \\
\text { Non-digital (ND) }\end{array}$ & Input & Task & $\begin{array}{l}\text { Designed for } \\
\text { multiple } \\
\text { orientations? }\end{array}$ & Posture & $\begin{array}{l}\text { Group } \\
\text { size }\end{array}$ & $\begin{array}{c}\text { Num. groups, } \\
\text { Experimental } \\
\text { design }\end{array}$ \\
\hline $\begin{array}{c}\text { Rogers and } \\
\text { Lindley (2004) }\end{array}$ & $\mathrm{D}$ & Single pen & $\begin{array}{l}\text { Travel } \\
\text { itinerary } \\
\text { planning }\end{array}$ & No & $\begin{array}{c}\text { H-sit } \\
\text { V-sit or stand }\end{array}$ & 3 & $\begin{array}{l}8 \text { (within subs) } \\
\text { In-the-lab }\end{array}$ \\
\hline $\begin{array}{l}\text { Inkpen et al. } \\
(2005)\end{array}$ & ND & Pens & $\begin{array}{l}\text { Route } \\
\text { planning }\end{array}$ & No & $\begin{array}{c}\mathrm{H}-\text { sit } \\
\mathrm{V}-\text { stand }\end{array}$ & 2 & $\begin{array}{l}6 \text { (within subs) } \\
\text { In-the-lab }\end{array}$ \\
\hline $\begin{array}{l}\text { Pantidi et al. } \\
\quad(2009)\end{array}$ & $\mathrm{ND}(\mathrm{V}), \mathrm{D}(\mathrm{H})$ & $\begin{array}{c}\text { ND-pens } \\
\text { D-multi-touch }\end{array}$ & $\begin{array}{l}\text { Concept } \\
\text { Mapping }\end{array}$ & Yes & Sit or stand & $9-10$ & $\begin{array}{l}4 \text { (between subs) } \\
\text { In-the-wild }\end{array}$ \\
\hline $\begin{array}{l}\text { Clayphan et al. } \\
\text { (2011) }\end{array}$ & $\mathrm{ND}(\mathrm{V}), \mathrm{D}(\mathrm{H})$ & $\begin{array}{l}\text { ND-pens } \\
\text { D-multi-touch }+ \\
\text { keyboards }\end{array}$ & $\begin{array}{l}\text { Marketing } \\
\text { Brainstorm }\end{array}$ & Yes & Stand & 4 & $\begin{array}{l}6 \text { (within subs) } \\
\text { In-the-lab }\end{array}$ \\
\hline $\begin{array}{l}\text { Potvin et al. } \\
\quad(2012)\end{array}$ & ND & Pens & $\begin{array}{l}\text { Software } \\
\text { design }\end{array}$ & No & Stand & 2 & $\begin{array}{l}10 \text { (within subs) } \\
\text { In-the-lab }\end{array}$ \\
\hline Our work & $\mathrm{D}$ & $\begin{array}{l}\text { Multi-touch + } \\
\text { keyboards }\end{array}$ & $\begin{array}{c}\text { Design } \\
\text { Brainstorm }\end{array}$ & Yes & $\begin{array}{c}\text { H-sit } \\
\text { V-sit or stand }\end{array}$ & $3-4$ & $\begin{array}{l}14 \text { (within subs) } \\
\text { In-the-wild }\end{array}$ \\
\hline
\end{tabular}

Table 2: Summary of horizontal and vertical orientation display studies (H: Horizontal, V: Vertical). Extended from Potvin et al. 2012

groups of 3-5 or more, it is even more pressing. This creates a new design constraint compared with vertical displays; for these, conventional screen layouts are likely to be effective since all users view them from the same orientation. However, for people sitting around a table, the interface designer needs to consider that text and other content that is oriented correctly for the user at one position will be upside-down or rotated for other users. This compromises easy scanning and reading of materials and affects the dynamics of interaction. Columns 6 shows an important aspect of physical layout, whether users are seated, standing or have a choice between these. Column 7 has group size, which interacts strongly with issues of orientation at the tabletop. Our work has groups of 3-4, as is common in classrooms, because it provides a good balance between rich collaboration and manageable group coordination. The final column, shows the extent of the studies in terms of the number of groups and indicates that all but one (Pantidi et al., 2009) used a within-subject study design. Importantly, it distinguishes lab studies from more in-the-wild settings. We note that all these studies involved adults.

An early and influential comparison was conducted by Rogers and Lindley (2004). Groups of three used pen-based hardware, similar to current pen-based electronic whiteboards. Three conditions were examined: a horizontal display; a vertical display; and a combination of both. Each display had a single electronic pen, which participants had to share. The task was to navigate to websites to find information, answering questions on a separate paper worksheet. The authors reported higher awareness for the tabletop - likely due to being seated side-by-side and the use of the table ledge to fill in the worksheet. By contrast, the vertical display was plagued with problems of pen changeover and physical layout - as participants sat away from the display, when completing the worksheet. When both displays were used together, each with their own pen, the task was accomplished much faster. The main conclusions: devices that encourage people to be physically near each other are likely to facilitate collaborative interactions, and the use of multiple inputs increases productivity.

Inkpen et al. (2005) explored: display angle, user arrangement, display size and the number of displays on how they influence face-to-face work. Four studies - each paper prototyped, examined each factor. They found horizontal interfaces afford different user placements, vertical displays afford glancing, and tilted displays are comfortable when used by one person - but not practical for groups. Five of the twelve participants commented on writing difficulties at the vertical display. Participants did not prefer 
one device over another. This work involved non-digital collaborative work and pairs; so we need to be cautious in assessing the implications for the context that is our focus. We note the difficulties participants raised with writing in the digital conditions.

Pantidi et al. (2009) compared low-tech and high-tech devices - post-it notes, pens, a (non-electronic) whiteboard, and a multi-touch tabletop. The study involved a workshop breakout session with groups of 9-10. The authors focused on participant equality. Three tasks were posed: (1) presentation and discussion; (2) build a concept map and (3) report to others in the workshop. Observations indicated writing on the wall was problematic; and the physical layout of the tabletop disadvantageous (located away from the main discussion area). For those who did use the tabletop, the interface was intuitive and allowed people to work in parallel. This study differs from ours on several dimensions: the lack of an interactive display at the wall, very large groups (9-10), and a three-phase task that proved problematic. However, it is the only one of these study conducted in-the-wild.

Clayphan et al. (2011) compared a non-interactive whiteboard (with multiple pens) to a multi-touch tabletop with keyboards. The task was brainstorming. The results showed the tabletop led to more egalitarian contributions, and more ideas produced. Groups at the whiteboard tended to select a scribe, resulting in turn taking - despite ample room for all to work together. The study pointed to the benefits of tabletops, and leveraging their affordances to scaffold team activities. This influences our own work, where we used an orchestration engine to faithfully implement a high level specification of the teacher's activity design, to aid with activity deployment.

Lastly, Potvin et al. (2012), compared pairs at non-interactive displays. They found the vertical displays afforded better support for face-to-face contact, though this result may well be due to the work involving pairs rather than larger groups. Orientation had little impact on equality of verbal and physical participation. There was decreased face-to-face contact at the tabletop, though likely due to posture issues, where participants stood over a table and were required to lean inward. The authors conclude that more research is required to better understand how to support collaborative tasks.

\section{Summary}

The body of work summarised in Table 2 motivated our second research question as it highlights how little work has compared horizontal and vertical SDGs and the many gaps in our understanding. It is notable that, across the five previous studies presented, only one was completely digital (Rogers and Lindley, 2004); yet the digital pens of that study that posed problems are quite different from current multi-touch SDGs. Only two accounted for multiple orientations in the horizontal condition (Clayphan et al., 2011; Pantidi et al., 2009). This neglects the key difference in design for tabletops to account for the inherent need to support effective interaction by people at different orientations. Further, size of groups varied - from pairs, where members can be comfortably side-by-side, in which case it may not matter that the task involves orientation-dependent data, to groups with three or more. For groups of three, the effect of orientation becomes more important, and with groups of four or higher, even more serious. Our work is the first to compare both vertical and horizontal multi-touch displays, with the design of the interface carefully taking account, the different orientations for the tabletop case. Importantly, we do this in the context of groups of 3-4 students, a typical size of many educational collaborative learning activities and being well accommodated around current large screen displays.

Importantly, all but Pantidi et al. (2009) were conducted in tightly controlled laboratory setups and none involved classroom settings. So most of this work involved artificial tasks, with less pressing constraints 
than those of a real classroom. Notably among these are tight time constraints of scheduled classes and the need for group sizes demanded by the learning goals.

Overall, there are large gaps in our understanding of horizontal versus vertical SDGs for small-group work in classrooms. As Table 2 shows, none of the comparative work has been in classrooms. The work comparing interactive whiteboards and tabletops for group work, conducted predominately in lab settings, suggests benefits for face-to-face collaboration at the tabletop.

\section{Study Design}

To address our two research questions, we designed an in-the-wild within-class-group study in the context of a curriculum component devoted to teaching brainstorming. Each of three tutorial class groups did three brainstorms, one in each of our three conditions:

1. a conventional classroom, with small tables and using index cards;

2. a tabletop classroom;

3. a vertical display classroom.

For our first research question, we wanted to compare the conventional classroom against the SDGenhanced classrooms. The related work just summarised indicates that there have been very few studies of SDGs in classrooms and none of them compared the learning environment with a conventional classroom for the same activity.

For the second research question, our focus was on comparing the tabletops and vertical displays. Here, too, our review of previous research highlights that there has been some serious work comparing these SDGs but little that has been in-the-wild and none in a classroom setting.

One important design choice was for an in-the-wild study. We wanted to gain insights into the research questions in a context that was as authentic a classroom setting as we could make it. This should make the results more meaningful for informing understanding of the ways that SDGs can serve small group learning in classrooms. This decision played a key role in selecting the learning activity, brainstorming; this was part of the curriculum in an established subject. So our conventional classroom condition could be based on previous practice.

We chose a within-class-group design for two main reasons: to reduce the effects of differences in ability and motivation between groups; and to satisfy the teacher that all students would have the same learning opportunities and experiences, so the design ensured perceived equity. This aspect of the design is in line with most of the work reported above.

The first part of this section explains the detailed design of the study in terms aspects experienced by the participants: the design of the learning activities; the design of the SDG applications, with both wall and table versions carefully crafted and tested to be well suited to that device; and the overall series of events in the full three conditions experienced by each learner.

The second part of this section explains our design of the data collection. This draws upon considerable literature about the evaluation of brainstorming. We also needed to identify how to assess the nature and quality of the collaboration. 


\section{Curriculum and Class Context}

Three learning activities were designed to fit into the curriculum of a second year subject called "Interaction Design Studio" in the Bachelor of Design Computing at the University of X. The subject has 6 contact hours per week, with three hours each week dedicated to studio work where students work either on small design activities or their design projects, supported by their teacher and tutors. Depending on the type of activity, the studio typically runs in different and sometimes multiple learning spaces. Class activities are generally designed to complement and build on lectures. These activities typically require students to work in small groups and end with a reflection session that involves the entire class.

For the week of our study (Week 6 in a 13 week semester), the studio activity in the curriculum aimed to help students learn and apply collaborative ideation methods. For this, the class was devoted to learning a brainstorming technique to develop ideas to a given problem brief, and students engaged in a number of brainstorms. In previous years, the teacher had designed the class around a brainstorming session with index cards. As brainstorming plays an important role in interaction design, the teacher decided to use different learning environments and associated technology-enhanced tools to support the group activity.

Importantly, the activities and the tools were designed and developed in close collaboration with the teacher to ensure that the design of the classroom activities was carefully crafted to make effective use of the technology-enhanced classroom settings. The activity was based on the established principles of Brainstorming (Osborn, 1953) which the students learned about in a preceding lecture. Importantly for gaining insights about a range of small group collaborative activities, the brainstorming involved three main phases: (1) idea generation, in which students worked in parallel in a divergent group work activity, as they were encouraged to follow the principles of brainstorming: focus on quantity, withhold criticism, welcome unusual ideas, and spark off others' ideas; (2) group categorisation and discussion of the ideas, a convergent and tightly interactive phase when the group worked together grouping similar ideas, to identify the most promising ones; and (3) group selection of the very best ideas, involving group consensus processes. Each of these calls for a different form of group work. Notably, the first phase is divergent, involving parallel generation of as many ideas as possible, employing processes such as cognitive stimulation (Dugosh et al., 2000), social comparison (Dugosh and Paulus, 2005) and group awareness (Dourish and Bellotti, 1992). The second and third stages are convergent, involving discussions and gaining agreement. So the design of the task ensures that it embodies important and diverse forms of small group collaboration.

\section{Topics}

The teacher set three topics (two from previous years). Each was expressed as a design challenge:

- Topic 1: to design a solution that helps students to remember their USB memory stick when leaving the computer or lab space (Figure 2).

- Topic 2: to design a solution that gives students better access to lecture slides and other materials provided by the lecturer.

Topic 3: to design a solution that provides students with wayfinding information for lecture theatres and lab spaces while on-the-go. 


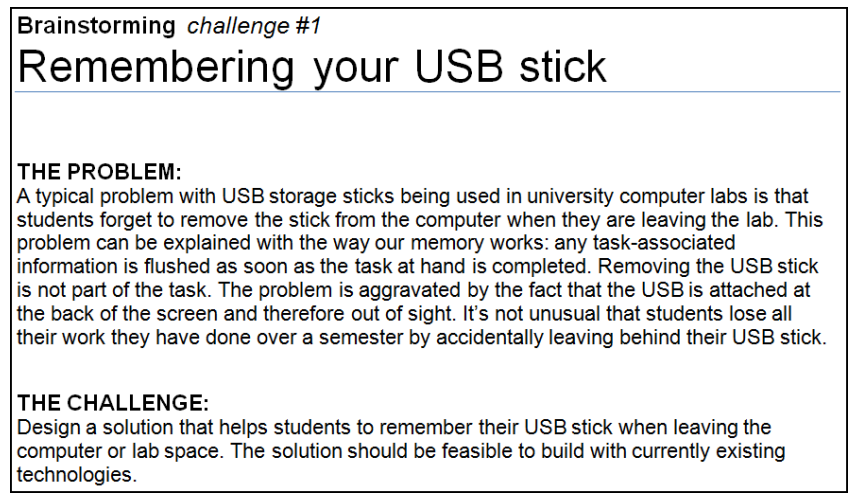

Figure 2: Example description of a topic handed to students, including: the problem; and the posed challenge.

\section{Learning Environments Overview}

All three learning environments used in this study are available at University of $X$ to conduct smallgroup activities for a number of regular classes as requested by the teachers. These are: a design studio, where teachers regularly conduct activities involving pens and paper; a multi-interactive vertical display setting; and a multi-tabletop classroom. We describe each environment and the learning application used.

\section{Design Studio for Paper-Based Activities}

This learning setting was identical to that used in previous years, and consisted of an open flat space with re-configurable furniture. For the purpose of the activity, each group worked at their own separate table. Students worked in groups of 3 or 4 . Students were issued with coloured index cards, each student using their own colour; to enhance accountability. Students were asked to write their ideas and categorise them as required. For categorisation, students wrote the name of a category on a card and grouped the idea cards around it. Students freely decided on the length and form in which they wrote ideas (Figure 3).

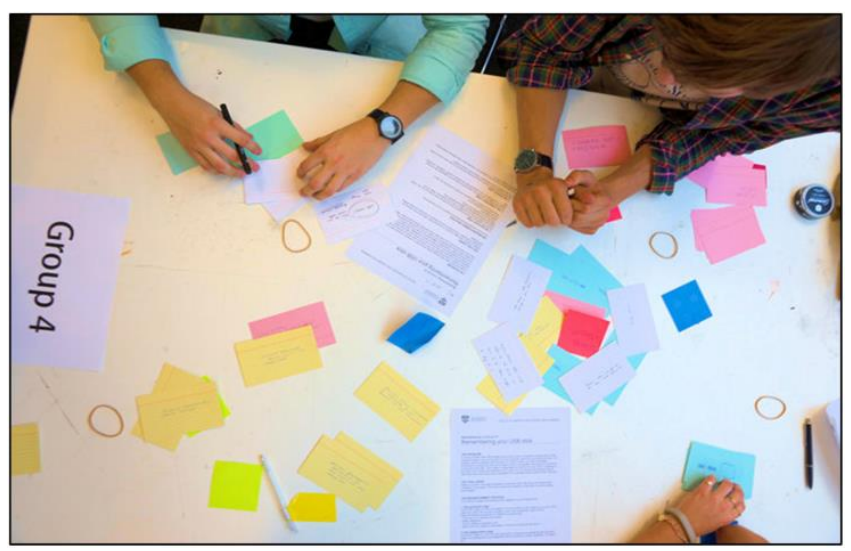

Figure 3: Paper based idea generation. 


\section{Multiple Interactive Vertical Displays Setting}

In the second setting, each group worked at a conventional table, and an interactive (46") vertical touchdisplay (Figure 4 - right). Each student was given a separate physical keyboard, so they could type ideas simultaneously, and have these appear on the vertical display. As the vertical displays were not moveable, we carefully designed the layout between the physical table (which was reconfigurable) and the interactive display. We explored several ways to position the table, wall and chairs, as shown in Figure 4 - left. Essentially, we considered the left layouts with learners in a row, compared with the right layouts, where the chairs were around the 3 edges of the table. We considered placing the table hard against the interactive wall (top) or with a gap for a standing area. We assessed each design in the classroom for reachability, screen visibility and ergonomics and conducted informal trials with small groups. The final chosen layout was arrangement \#4 - This enabled students to sit in a semi-circle for the idea generation phase, gaining much of the benefit of being able to face each other (as in the tabletop condition). It also placed the vertical display at a comfortable reading distance for all - during the idea generation stage, when there was no need to interact with the touch-display. For the group categorisation and discussion phase, at least one student needed to stand to interact with the display. The space between the table and the display made it possible for several students from the group to stand at the display, to interact with it for the group discussion. An important merit of this layout is that the divergent stage (idea generation) is clearly marked; when it ends, at least one student needs to move (stand and interact with the display) for the convergent discussion (idea categorisation).
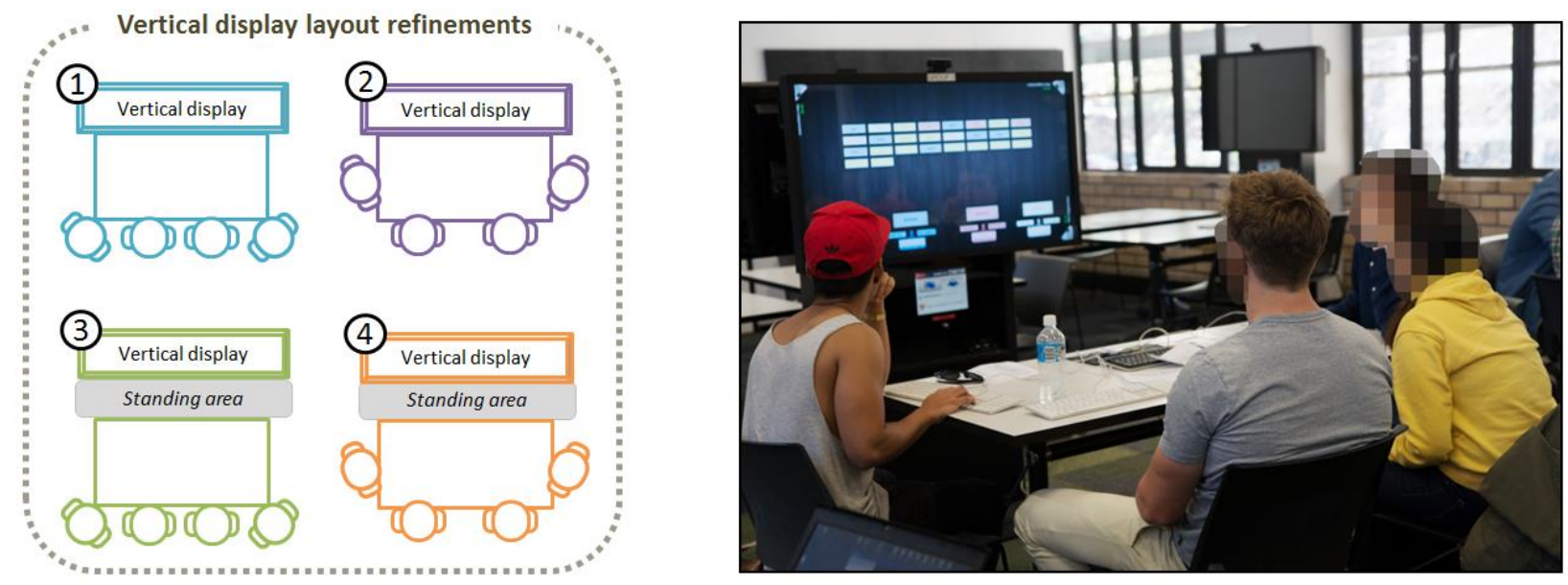

Figure 4: Left: Vertical display arrangements evaluated. Right: An interactive vertical display in the classroom (Layout arrangement \#4).

\section{Multiple Interactive Tabletop Classroom}

The third setting consists of five (46") interactive tabletops with a keyboard for each user (Figure 5). The tabletops were in fixed positions, a physical classroom constraint. Each tabletop came with a system that could differentiate who was touching each part of the interactive surface (Martinez-Maldonado et al., 2011). The construction of this setting is grounded on principles of classroom orchestration and multi-tabletop settings as defined in Kharrufa et al. (2013b). In this setting, students can interact both face-to-face and side-by-side. At the same time, all group members have similar opportunities to interact with the interactive surface. As stated earlier, these interaction affordances, compared with the vertical display setting, have positively impacted the ways groups collaborate and generate ideas (Clayphan et al., 2011; Rogers and Lindley, 2004). 


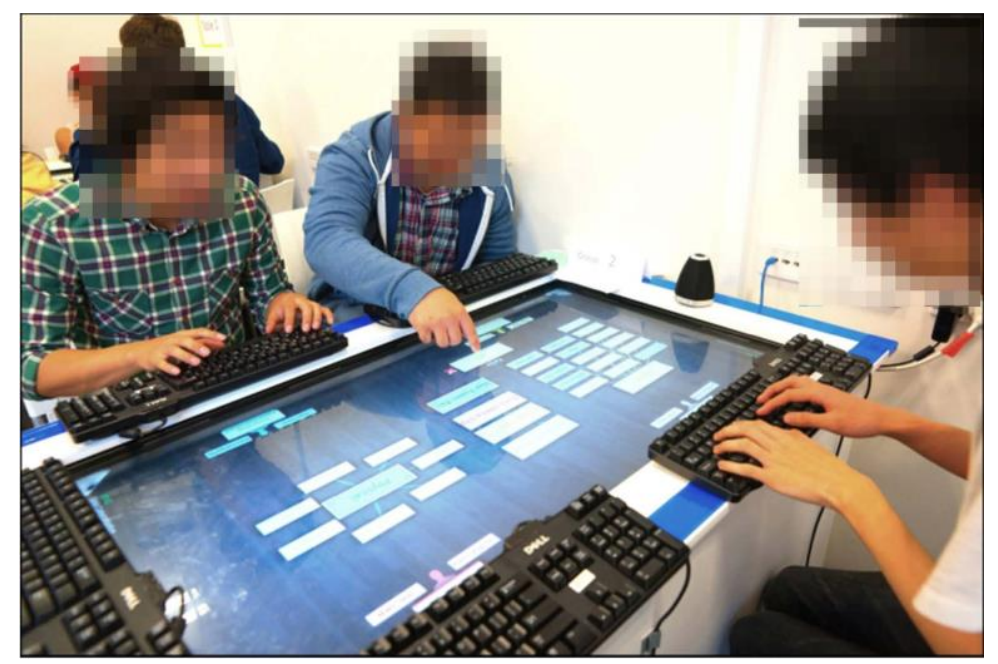

Figure 5: An interactive tabletop in the classroom.

\section{Brainstorming Application Overview}

For both the interactive vertical displays and tabletops, we used the same brainstorming application, based on a scripted collaboration tool called ScriptStorm (Clayphan et al. 2014). The application was designed to work with both forms of interactive touch devices, with the vertical and horizontal configurations. The system featured an orchestration engine, where a teacher pre-specified the classroom activity and the timing of the phases: ideation; categorisation (discussion and grouping); and best-idea selection. This helped manage orchestration load on the part of the teachers, allowing them to easily control the technology, and progress each of the activity phases. A previous study (Clayphan et al. 2014) demonstrated the application as both quick to learn and easy to use, therefore allowing more time for students to brainstorm and less time required for interface familiarisation. The interface used multiple physical keyboards at the idea generation phase. This affords fast idea typing, avoiding problems of on-screen touch keyboards and handwriting issues - which has been documented in other brainstorming studies at similar groupware devices (Clayphan et al., 2011; Jaco et al. 2014).

There was one difference between the configurations for the vertical displays and the tabletops. This occurred during the first phase (ideation). As students typed the ideas, they appeared top-down on the vertical display (Figure 6). For the tabletop, ideas initially appeared around a circle in the middle of the table (Figure 7). This was done to allow readability of ideas across seating positions around the screen for each condition. In addition, the use of a digital avatar (the rectangle with a coloured user), was a link between the physical student and where the student was seated in reference to the interactive display. After the ideation phase, students could orient (and move) ideas however they wished. These particular layouts were both informally tested for text readability and typing comfort (with a separate set of students) for each particular technology type. 


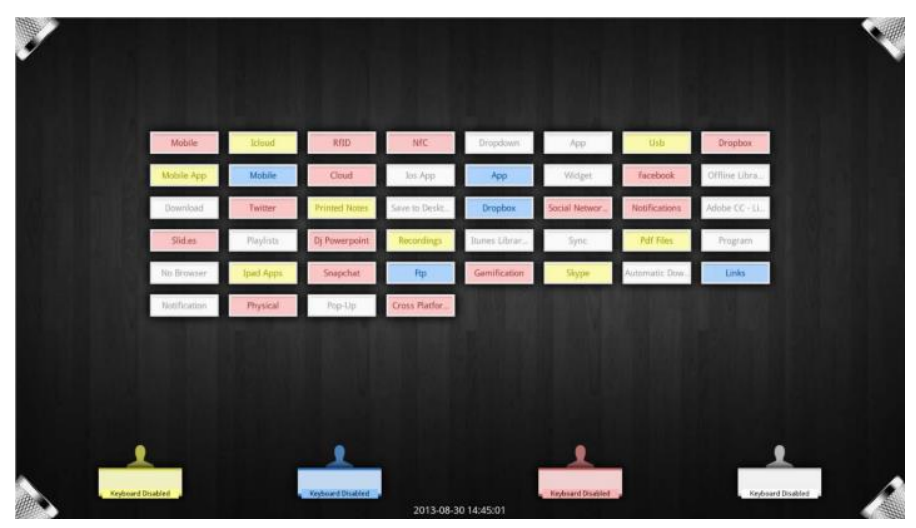

Figure 6: The vertical display interface, with ideas placed top-down.

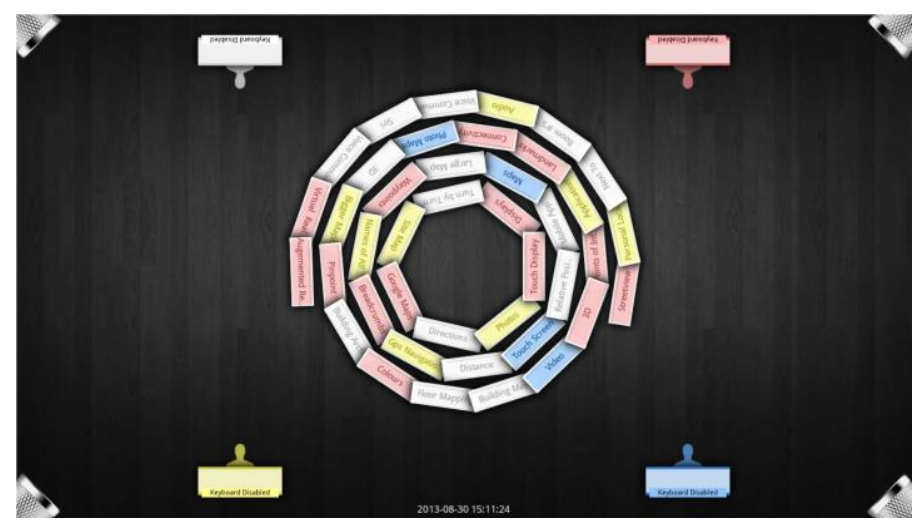

Figure 7: The tabletop interface, with ideas placed in a concentric pattern.

\section{Participants}

Participants consisted of 51 students (31 male, 20 female) who attended the studio in Week 6 (consent obtained in the week prior). Students were first asked a set of general background questions. Most (90\%) were enrolled in a Bachelor of Design Computing, the remainder being from a study abroad program. Thirty-five percent of participants had used an interactive tabletop before (touch screen directories, art installations, and design projects), $46 \%$ an interactive whiteboard before (mainly smartboards at school), and $22 \%$ had used both. No students had previously been exposed to the particular brainstorming software used during the study. However, $75 \%$ reported performing brainstorming activities in the past, as part of regular class activities.

\section{Small-group Classroom Activity Design}

The 51 students met at their regular classroom at the start of their studio and were divided into 3 equal sections (A, B and C), each section having 4 or 5 small groups, each with 3 or 4 students. Each section followed a pre-determined ordering sequence for the learning environments and topics. This allowed each student to experience each environment, as well as each topic once in the total time of the studio. The teacher counter-balanced the topics with the learning settings in such a way that each topic was discussed in all the environments (by different groups). 


\begin{tabular}{|c|c|c|c|c|c|c|c|c|c|}
\hline Time in minutes & 15 & 10 & 30 & 10 & 30 & 10 & 30 & 10 & 35 \\
\hline \multirow{3}{*}{$\begin{array}{l}\text { Students } \\
\text { separated into } \\
\text { sections and } \\
\text { groups }\end{array}$} & $\begin{array}{l}\text { Section A } \\
\text { (4 groups) }\end{array}$ & Walk & $\begin{array}{l}\text { Tabletop } \\
\text { (Topic 1) }\end{array}$ & Walk & $\begin{array}{l}\text { Index Cards } \\
\text { (Topic 2) }\end{array}$ & Walk & $\begin{array}{l}\text { Vertical Display } \\
\text { (Topic 3) }\end{array}$ & Walk & \multirow{3}{*}{$\begin{array}{l}\text { Reflection - all } \\
\text { students at the } \\
\text { lecture theatre. }\end{array}$} \\
\hline & $\begin{array}{l}\text { Section B } \\
\text { (5 groups) }\end{array}$ & Walk & $\begin{array}{l}\text { Vertical Display } \\
\quad(\text { Topic 2) }\end{array}$ & Walk & $\begin{array}{l}\text { Tabletop } \\
\text { (Topic 3) }\end{array}$ & Walk & $\begin{array}{l}\text { Index Cards } \\
\text { (Topic 1) }\end{array}$ & Walk & \\
\hline & $\begin{array}{l}\text { Section C } \\
\text { (5 groups) }\end{array}$ & Walk & $\begin{array}{l}\text { Index Cards } \\
\text { (Topic 3) }\end{array}$ & Walk & $\begin{array}{l}\text { Vertical Display } \\
\quad(\text { Topic } 1)\end{array}$ & Walk & $\begin{array}{l}\text { Tabletop } \\
\text { (Topic 2) }\end{array}$ & Walk & \\
\hline
\end{tabular}

Table 3: The activity plan of the brainstorm study within the 3-hour studio session of the subject.

The teacher's activity plan with the sequence of technology and topics is shown in Table 3. Groups were formed randomly (a requirement by the teacher to prevent students forming groups with only their close friends). Each student received a ticket specifying Section, Group and Colour (colour being the coloured avatar for the student in the tabletop and vertical display conditions; and the colour of the index cards). Each student then completed three brainstorm activities (within their group), one at each venue.

As the venues were at different locations on the campus, groups had to walk between them, staying with their section (see Table 3, 10 minutes for walking between venues). Each brainstorming session lasted approximately 30 minutes (in-line with previous years), with:

- 5 minutes for familiarisation with the learning space and a sample demonstration

- 5 minutes to read the design problem (as well as instructions for how to brainstorm)

- 5 minutes for idea generation

- 10 minutes for idea categorisation (discussion and grouping)

- 2 minutes for writing down (on a special card) what the group considered their best idea from the session (for use later on)

After the three sessions, students filled in a post-experiment questionnaire, reporting their experiences of each environment and then all groups met back at a common lecture theatre, and shared their best ideas (see last column of Table 3). Each topic was considered in turn by the teacher. A delegate from each group was given a maximum of 30 seconds to pitch the groups' best idea to the rest of the class. The idea was then affixed to a (non-interactive) whiteboard. After all groups had presented their best idea on the specified topic, students voted by placing stickers, on the idea they thought was best. This process was repeated for all three topics.

We illustrate the teacher's design with the example of Section A (see Table 3). The 4 groups, once formed, walked to the multi-tabletop classroom to work on Topic 1; after completing the 30-minute activity, they walked to the design studio to work on Topic 2 using index cards. Then they walked to the multi-interactive vertical display classroom for Topic 3. They finally went to a common lecture theatre to meet their teacher for the reflection activity, which involved the entire class.

\section{Multiple Dimensions of Study and Sources of Evidence}

We identified six dimensions of students' collaborative idea generation, as listed in Table 4. For each we identified sources of evidence for analysis. The first, idea generation, is the count of ideas generated. 


\begin{tabular}{cccc}
\hline & Application & Sources of evidence & \\
Dimensions of study & Observations & Students \\
\hline Idea generation & $\bullet$ & & $\bullet$ \\
\hline Mutual awareness & $\bullet$ & $\bullet$ & $\bullet$ \\
\hline Participation strategies & & $\bullet$ & $\bullet$ \\
\hline Level of interest & $\bullet$ & $\bullet$ \\
\hline Learning space configuration & & $\bullet$ \\
\hline
\end{tabular}

Table 4: Multiple dimensions of study and sources of evidence (application logs and index cards; students questionnaires and ratings and systematic observations).

This is commonly used (Isaksen, 1998) to assess brainstorming, as it follows the principle of brainstorming, that the quantity of ideas correlates with the best creative outcomes (Osborn, 1953).

Mutual awareness refers to each person's awareness of contributions by other group members. Our design, with colour coded ideas, enabled students to easily see who had created each idea.

Participation strategies referred to the degree of cooperation versus independent work; in the ideation phase, part of the power of the approach comes from taking inspiration from each other's ideas. So cooperation in this phase means working so that this is possible and using other's ideas to spark new ones. By contrast, working independently, without letting others see one's ideas is against the spirit of the brainstorming technique. The next dimension is interest. This refers to student perception of the technology as increasing their engagement in the learning activity. Finally, we evaluated an aspect that was very important for the teacher, the quality of the ideas generated. Quality of ideas were evaluated in multiple ways: the ideas at the reflection section - by students voting; a separate ranking from the main teacher and two tutors; and a week later the main instructor and one tutor rated all ideas (on a scale of 1 to 5,5 being best).

To understand these dimensions of the study, we triangulate evidence from three sources. Table 4 shows the relationship between these sources (columns 2-4) and the dimensions that each targets (column 1). The first source of evidence (column 2) is the physical cards from the conventional class setting. For ideas from the touch interfaces, application logs were used.

For the second source of evidence - observations (column 3), 6 observers were involved. An observer was stationed in each learning space, and there was one observer assigned to each section. The stationary observer in the learning space recorded the dominant strategy employed in the idea generation and idea categorisation phases, as well as whether groups stood or sat. Strategy types were defined by the teacher and research team, to describe how individuals worked in the team together. Strategy types were not mutually exclusive. They were:

- Co-operation - where students appear to be actively working together.

- Independent - where students (or the majority of students) appear to be working alone.

- Leader - where a student (or students) took charge and directed the rest of the group.

All observers were briefed and undertook training on how to code teams. Writing space was also provided on the forms used by the stationary observer, to aid recording of the dominant strategy choice as well as any notable observations. 
The remaining three observers (the moving observers) were each assigned to one section. They followed their section, walking from one learning environment to the next. These observers recorded the activity of each individual student using three possible values:

- Constructing - if the student was observed either creating an idea or having their hands on the technology.

- Monitoring - if the student was speaking or involved in the idea generation process without interacting with the technology.

- Disengaged - if the student was looking at other groups, distracted by a mobile phone or not paying attention to others.

Each observation recorded by the moving observer was systematically done every half-minute for each group - which meant the observer visited that group (standing back, not interjecting or disrupting the group), viewing what each participant was doing, recording this observation on their sheet against the relevant code, and then moved to the next group. This meant one judgement per group was made every 2-3 minutes. In this way, the moving observers recorded multiple samples for each group during the whole activity. All moving observers were trained how to code students.

Lastly, we obtained information from students (column 4). This was in the form of a post-experiment questionnaire. In most of these questions, students were asked to answer on a 6-point Likert scale (for each learning environment if applicable) about each of the dimensions of the study (column 1). They were also asked to optionally comment on their answers. Finally, we captured the students' ratings of each group's best ideas as described in the previous sub-section.

\section{Results}

Our research questions involve two inter-related comparisons: RQ1 compares the conventional learning condition against the SDGs and RQ2 compares the tables and walls. So, this section presents the data collected in terms of the dimensions we identified (summarised in Table 4). In the next section, our discussion of the results will return to the research questions. Our study design ensured that there was data collected from the students about their perceptions on each dimension. Table 5 summarises the Likert results from the post-experiment questionnaire.

\section{Idea Generation}

Literature on brainstorming emphasises the importance of the number of ideas generated, with it claimed to correlate with quality (Osborn, 1953). Table 6 summarises the number of ideas generated in terms of the mean and the standard deviation (SD) by groups in each section, across learning environments (tabletops; interactive vertical displays; and index cards) and for each topic (1 - USB, 2 - Lecture Slides, and 3 - Wayfinding). The bottom row of Table 6 shows that students generated fewer ideas when they were working with index cards (mean of 12 ideas) compared with the technology enhanced conditions (mean of 21+). We note that the ranges between learning environments are considerable, with sections $\mathrm{A}$ and $\mathrm{B}$ following a general pattern of producing more ideas at the technological conditions than the pen and index cards condition. Section B has the highest mean and standard deviation in each learning environment; due to two particularly productive groups. The numbers of ideas produced are now statistically examined. 


\begin{tabular}{|c|c|c|c|}
\hline \multirow{2}{*}{ Friedman test } & \multicolumn{3}{|c|}{ Mean (SD) on Likert Data } \\
\hline & Tabletops & Vertical Displays & Index Cards \\
\hline $\begin{array}{c}\chi^{2}(2)=5 \\
\mathbf{p}=\mathbf{0 . 0 5}\end{array}$ & $5.29(0.69)$ & $4.92(0.76)$ & $4.73(1.21)$ \\
\hline
\end{tabular}

Post-hoc Wilcoxon signed rank tests with Bonferroni continuity correction, showed significant differences between:

- Tabletops and Vertical Displays $(p=0.02, r=0.24)$

- Tabletops and Index Cards $(p=0.0147, r=0.25)$

Q2. I was able to easily understand what was required of me in order to complete the brainstorm

$$
\begin{gathered}
\chi^{2}(2)=1.86 \\
p=0.40
\end{gathered}
$$

$5.31(0.64)$

$5.22(0.69)$

$5.3(0.57)$

Q3. The method of brainstorming helped me generate ideas

$$
\begin{gathered}
\chi^{2}(2)=3.78 \\
p=0.15
\end{gathered}
$$

$5.16(0.67)$

$5.04(0.72)$

$4.92(0.88)$

Q4. Overall, I was able to understand how the technology responded to my input

N/A $\quad 5.14(0.79) \quad 4.98(0.83)$

N/A

Note: As only two matched groups in this question, a Wilicoxon signed rank test was run (no effects found).

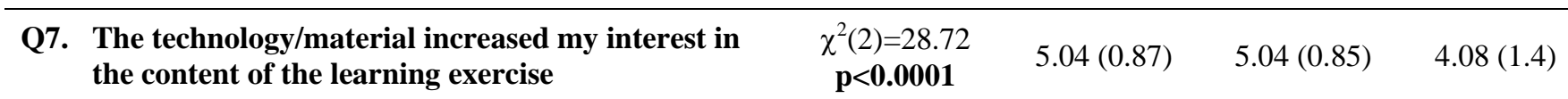

Post-hoc Wilcoxon signed rank tests with Bonferroni continuity correction, showed significant differences between:

○ Tabletops and Index Cards ( $p<0.0001, r=0.42)$

○ Vertical Displays and Index Cards $(p<0.0001, r=0.43)$

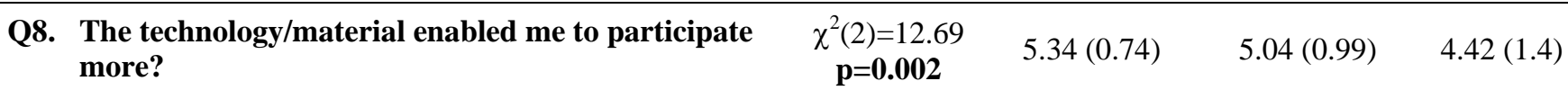

Post-hoc Wilcoxon signed rank tests with Bonferroni continuity correction, showed significant differences between:

○ Tabletops and Index Cards $(p=0.00075, r=0.39)$

- Vertical Displays and Index Cards $(p=0.026, r=0.23)$

\begin{tabular}{lllll}
\hline Q9. The technology/material supported collaboration & $\begin{array}{c}\chi^{2}(2)=4.89 \\
\mathbf{p = 0 . 0 8 7}\end{array}$ & $5.28(0.67)$ & $4.96(0.92)$ & $4.78(1.12)$
\end{tabular}

Post-hoc Wilcoxon signed rank tests with Bonferroni continuity correction, showed significant differences between:

- Tabletops and Vertical Displays $(p=0.015, r=0.26)$

- Tabletops and Index Cards $(p=0.05, r=0.2)$

$\begin{aligned} & \text { Q10. Did you find the learning space (technology/ } \\ & \text { furnishings, etc.) supported the activity? }\end{aligned}$
$\begin{gathered}\chi^{2}(2)=6.02 \\ \mathbf{p = 0 . 0 4 9}\end{gathered}$
$\begin{aligned} & \text { Post-hoc Wilcoxon signed rank tests with Bonferroni continuity correction, showed significant differences between: } \\ & \circ \quad \text { Tabletops and Index Cards }(p=0.0498, r=0.20) \\ & \circ \quad \text { Vertical Displays and Index Cards }(p=0.03, r=0.22)\end{aligned}$

Table 5: Post-Experiment Likert Questionnaire Quantitative Results Summary.

Significant items for $\mathrm{p}<0.1$ are bolded. Post-hoc Wilcoxon signed rank tests are reported for significant pairwise items.

Likert data range is from 1 to 6 (where 6 is strongly agree).

A two-way ANOVA (factors: 'Topic' and 'Learning Environment') with type III SSs, threshold alpha $=.05$ was conducted. Students who did not take part in all three brainstorms - either due to late arrival or early departure from class were removed. A significant effect was found for the Learning Environment $\left(\mathrm{F}(2,30)=4.75, \mathrm{p}=0.02\right.$, partial $\left.\eta^{2}=0.24\right)$. No other statistically significant main/interaction 
effects were found (alpha=.05) (i.e. Topic $p=0.29$, and Topic: Learning Environment p=0.12). Post-hoc Tukey HSD tests on the learning environment revealed the mean difference was significant for index cards and tabletops $(p=0.035)$ and index cards and vertical displays $(p=0.024)$. Levene's test did not show a violation of homogeneity of variances $(\mathrm{F}(8,30)=2.04, \mathrm{p}=0.075)$.

In the post-experiment questionnaire, we asked the students to rate the statement:

\section{"Q2: I was able to easily understand what was required of me in order to complete the brainstorm"}

for each learning environment, where this was rated on a 6-point Likert scale from 1 to 6 , where 6 meant total agreement (students' rating: tabletops -5.31 , vertical displays -5.22 , index cards -5.3 ). No significant difference was found. This indicates that students considered that they understood the task, and could complete it in each learning environment. Additionally no significant differences were attributable to the brainstorm method employed at the three learning spaces (Q3: The method of brainstorming helped me generate ideas), nor in the understanding of how to use the technology (Q4: Understanding how the technology responded to input).

Overall, both the tabletop and vertical display devices enabled students to create more ideas and faster than the conventional classroom. However, we also wanted to understand the features of the technologies and the cards that may have contributed to such an effect. For this, we triangulated results with the students' responses, on:

\section{"Q1: I was able to represent my ideas about the topic".}

Student ratings showed they preferred the multi-tabletop learning environment against both the vertical displays and the index cards (students' rating: tabletops -5.29 , vertical displays -4.92 , and index cards - 4.73). The tabletop differed significantly from the vertical display (Wilcoxon signed rank test, $\mathrm{p}=0.02$, $\mathrm{r}=0.24$ ) and the index card environments (Wilcoxon signed rank test, $\mathrm{p}=0.0147, \mathrm{r}=0.25$ ). Thirty-nine students left an optional comment. For tabletops: 18 positive, 3 negative; for vertical displays: 12 positive, 3 negative; and for index cards: 9 positive, 3 negative. Students described some of the preferred affordances of tabletops that they thought helped them work more collaboratively. For example: "the tabletop was the easiest to use because [we] could sit around it easily and discuss our work"; "[the] tabletop makes [idea generation] much faster than [the] vertical display because [we] don't have to stand up"; and "[the] tabletop makes it faster for [us] to edit or add anything to the ideas". This was also partially confirmed in

"Q9: The technology/material supported collaboration (working together) within my group”,

with the tabletops approaching a significant effect $\left(\chi^{2}(2)=4.89, \mathrm{p}=0.087\right)$ between both vertical displays and the index cards.

Students' free comments for this question again highlighted the benefits of both technological environments over the index cards, because the technology enabled them to generate more ideas by typing, compared with writing. Twenty percent of the students (10/51) commented that typing was much easier than handwriting. They commented on the readability of the ideas, favouring the vertical displays, with comments such as: "the vertical display was the easiest to read, so I engaged really well with others' ideas" and "the interactive displays supported us sharing and clarifying our ideas by displaying them together while the index cards did not force us to show/explain our ideas". 


\section{Participation and Group Strategies}

This aspect was studied in terms of three collected data sources. One of these was student responses in the questionnaire; the others from the two observer sets. We asked the students to answer the question "Q8: Did the technology/material enable you to participate more?"

Ratings were higher for the technology-enhanced classrooms:

- tabletops: $5.34(0.74)$

- vertical displays: $5.04(0.99)$

- index cards: $4.42(1.4)$

A Friedman test over 47 Likert responses revealed a significant effect $\left(\chi^{2}(2)=12.69, p=0.002\right)$. Post-hoc Wilcoxon signed rank tests revealed significant differences between:

- tabletops and index cards ( $\mathrm{p}=0.0001, \mathrm{r}=0.39)$

- vertical displays and index cards $(\mathrm{p}=0.03, \mathrm{r}=0.23)$

Of the 17 students who left an optional comment, there were, for tabletops: 7 positive, 1 negative; for vertical displays: 6 positive, 1 negative; and for index cards: 1 positive, 3 negative. Some representative students responses were as follows: "[I] instantly [saw] other team members' contributions [at] the interactive displays [which] helped me to generate more ideas. When [the] index cards [were used], ideas were kept to oneself more" and "the displays made it very easy to contribute ideas".

An interesting observation (noted on review of the ideas) in the index card environment was that 4 students in 2 groups, all from Section C (the first to use index cards), took the time to draw and sketch ideas, instead of writing, for example drawing a wireframe of a mobile application. This was also reflected in the comments "[index cards were] more flexible for drawing ideas, but hand-writing is slower"; and "[there was] freedom to sketch". It was only this first index-card group who did any drawing, which might indicate a possible order effect of the conditions. Notably, some students kept index cards to themselves, as in Figure 8. In such cases, with the student looking down at the card to create an idea, it is likely that they stopped observing what other group members were doing.

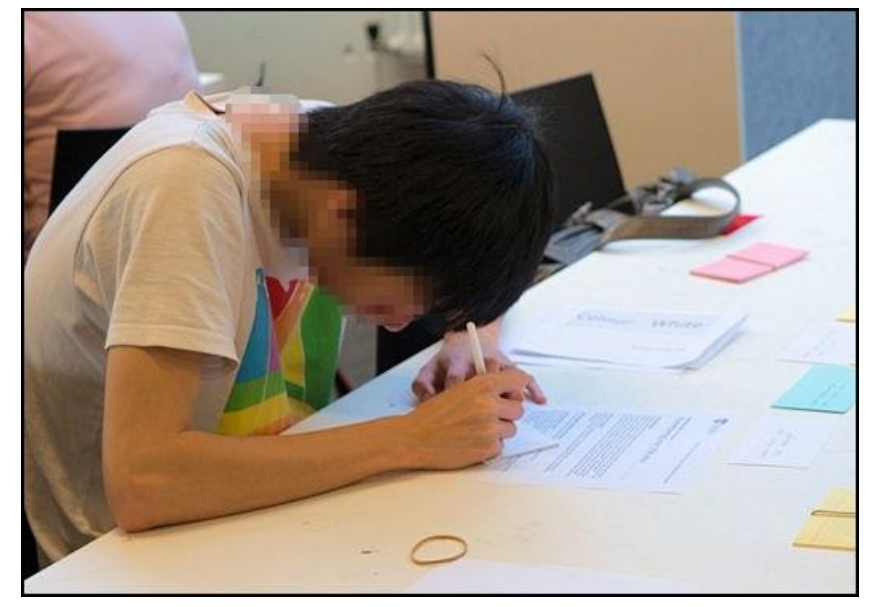

Figure 8: Index Cards. A student with their head down, focusing on their own index card. 
Table 7 summarises the observations by the stationary observers, for the dominant strategy each group employed. The observations confirm that most of the cases of students working independently happened in the index cards setting. The entry 'leader' indicates a point when one person took charge to direct the group. In fact, for this ideation phase, both tabletop and wall display resulted in cooperation in almost all cases; for the index cards, just 5 of the 13 groups displayed cooperation. The strategies employed during the discussion phase were predominately cooperation for all learning environments.

\begin{tabular}{cccc}
\hline $\begin{array}{c}\text { Section/ } \\
\text { Group }\end{array}$ & Tabletop & $\begin{array}{c}\text { Interactive } \\
\text { Vertical Displays }\end{array}$ & Index Cards \\
\hline A1 & Cooperation & Cooperation & Cooperation \\
A2 & Cooperation & Cooperation & Independent \\
A3 & Cooperation & Cooperation & Independent \\
A4 & Cooperation & Cooperation & Independent \\
B1 & Cooperation & Cooperation & Independent \\
B2 & Cooperation & Cooperation & Independent/Leader \\
B3 & Cooperation & Cooperation & Cooperation \\
B4 & Cooperation & Cooperation & Independent \\
B5 & Independent & Independent & Cooperation \\
& & Cooperation & Independent \\
C1 & Independent & Cooperation & Independent \\
C2 & Cooperation & Cooperation & Cooperation \\
C3 & Cooperation & Cooperation & Cooperation \\
C4 & Cooperation/Leader & Cooperation & N/A (group late to class) \\
C5 & Cooperation &
\end{tabular}

Table 7: The participation strategies observed during the idea generation stage.

Table 8 summarises data from the moving observers of each section. The table shows the percentage of the observations (recorded at 30 seconds intervals) in the categories: constructing, monitoring, or disengagement. The means for each environment were similar. This supports the conclusion that students in the technology conditions generated more ideas in the same period, rather than this being an effect due to the students themselves. In particular, students in the index cards condition, who spent $50 \%$ of their time constructing ideas, were on average only $60 \%$ as productive, in terms of the number of ideas generated, when compared to the two technology-enhanced conditions.

\begin{tabular}{cccc}
\hline & \multicolumn{3}{c}{ Learning Environments } \\
\hline & Tabletop & Vertical Displays & Index Cards \\
\hline Constructing: & $48 \%$ & $55 \%$ & $50 \%$ \\
\hline Monitoring: & $44 \%$ & $44 \%$ & $49 \%$ \\
\hline Disengaged: & $5 \%$ & $1 \%$ & $1 \%$ \\
\hline
\end{tabular}

Table 8: The proportion of behaviour observed in each learning environment during the idea generation phase. 


\section{Mutual Awareness}

In this section we analyse the impact of the design of each learning environment on students' mutual awareness. For this, we asked students about the way the physical spaces affected their participation in their groups and their awareness of others' contributions. First, for the multi-tabletop environment, students highlighted that the technology allowed them to work face-to-face while, at the same time, all students could type or touch the interface. Students described this as follows: "the tabletop allowed everyone to contribute and discuss more" and "tabletops [were] best because you are facing everyone". Students mentioned that working around the same interface gave them a better sense of team and being aware of others' actions (similar to that reported in Rogers and Lindley (2004)). In the words of one student: "it was easier to see everyone else's ideas and help generate my own on [the] tabletop, as you could flip and move the ideas". The vertical displays made it easier for students to quickly read all ideas at once; by contrast, some tabletop text was upside down for some students. This aspect of the design was intended to spur discussion, with individuals moving and reorienting ideas as needed. Students saw the vertical display as better suited for shared awareness of the group ideas. A student described this: "for the vertical display, the team was able to clearly see the ideas; the tabletop wasn't as effective. Index [cards] was also good but it could get messy at times".

Some students (15/33), commented on disadvantages of the index cards - referring to illegibility of handwriting, and how that made it hard for them to both present and interpret other members' cards. In terms of awareness, one commented: "index cards [were] hard to read with different handwriting". Additionally, students noted that handwriting ideas was slow, and so index cards did not allow them to participate as much as they would have liked to. Student comments also referred to the need to focus more on writing than sharing their ideas. One student described this as: "[when using index cards] we spent more time writing/drawing rather than talking about our ideas". By contrast, another student indicated that this was a positive affordance of using paper; they said they could "write out ideas without other people seeing them until you're finished". However, this violates the goals of the collaborative activity (as per the method taught by the teacher). The data from Table 7, already discussed, confirms this disadvantage of the conventional classroom for collaborative work.

Overall, students perceived that the learning environments had different affordances for mutual awareness. Tabletops were seen as enabling the whole group to work directly with the digital content and discuss ideas face-to-face. In the discussion phase, the readability problems of text, due to orientation, encouraged more equal interaction with the ideas, regardless of who had created them. Interactive vertical displays offered an unconstrained view of the entire set of ideas; but in the discussion phase, less equal interaction with the content was observed. The paper-based setting allowed students flexibility to write and sketch ideas but this made it harder to share and be aware of others' contributions.

\section{Level of Interest and Disengagement}

To measure the level of interest during the learning activity in each setting, we asked students to rate and comment on the statement

"Q7: The technology/material increased my interest in the content of the learning exercise”

The mean responses for both the tabletop and vertical display environments were 5.04 (agree); and 4.08 (somewhat agree) for index cards. A Friedman test over 49 Likert responses revealed a significant effect $\left(\chi^{2}(2)=28.72, p=0.000001\right)$ for the learning environment condition. Post-hoc Wilcoxon signed rank tests 
showed the difference was significant; between each of technology-enhanced settings and the index cards condition:

- tabletops and index cards ( $\mathrm{p}=0.0001, \mathrm{r}=0.39)$

- $\quad$ vertical displays and index cards $(\mathrm{p}=0.03, \mathrm{r}=0.23)$

Of the 17 students who left an optional comment, there were, for tabletops: 10 positive, 0 negative; for vertical displays: 9 positive, 0 negative; and for index cards: 0 positive, 4 negative. Students explained their answers and, again commented on having to physically write on the index cards, here as a deterrent to their interest: "writing [on index cards] was messy and tiring/ demotivating"; "not a good presentation for others"; "lost interest in writing, stayed demotivated"; and "I hate writing". By contrast, other comments indicated that students found the technological media to work well, explaining their interest as follows: "Interesting medium = more idea flow"; "ideas flowed for the tabletop"; "the layout and medium [tabletop] to support the work was professional and inspiring, paper was boring and tiring"; "interesting medium [vertical display] allows flow of creativity whereas boring paper and pen is demotivating and tiring"; "the technologies made the exercise more engaging and more of a group effort"; and "[the] vertical [display] and tabletop were engaging and we felt like a group... the cards made me feel more isolated".

Triangulating this evidence with the external observations (from the moving observers), some extent of disengagement was registered for all the learning environments. Table 8 shows that there was no significant difference in the number of times students were observed to be disengaged $(5 \%, 1 \%$ and $1 \%$ of the observation samples for tabletops, vertical displays and index cards settings). While it may not be evident from our particular disengagement measure - which recorded levels at discrete time intervals (which meant 2 or 3 observations for each individual over the course of the ideation), the qualitative feedback appears to suggest that the new technologies were welcomed, and enhanced students' interest.

\section{Learning space configuration}

For the study, the teacher adapted each space so that up to 20 students could work at a once (3-4 students per group). We asked students to rate and explain their response to the following:

\section{"Q10: Did you find the learning space (technology/ furnishings, etc.) supported the activity?"}

Their ratings showed that they preferred both of the technology-enhanced learning environments (average students' rating for tabletops and vertical displays, 5.0) over the regular studio space (index cards, 4.6). This was a small but statistically significant difference, confirmed with a Friedman test on the 47 Likert responses $\left(\chi^{2}(2)=6.02, \mathrm{p}=0.049\right)$. Post-hoc Wilcoxon signed rank tests showed significant differences between the tabletop and index cards $(\mathrm{p}=0.049, \mathrm{r}=0.20)$ and between the vertical displays and index cards $(\mathrm{p}=0.03, \mathrm{r}=0.22)$.

For all of the learning environments, we noted that students never attempted to alter the learning space configuration of the activity. The comments from students confirm satisfaction with the layout: "Seating us together in 4's helped."; "[the] tabletop had a good connection between generating ideas and having them displayed instantly in front of you". However, we observed a problem in some cases with the vertical displays for collaboration, also reported in Rogers and Lindley (2004). Figure 9 illustrates this for a group where three students stood near the board, excluding one student. We note, however, that in this case, the vertical display was very effective for the three people shown, the group size for the earlier work by Rogers and Lindley. It was our larger groups that had this problem. Other groups adopted a 


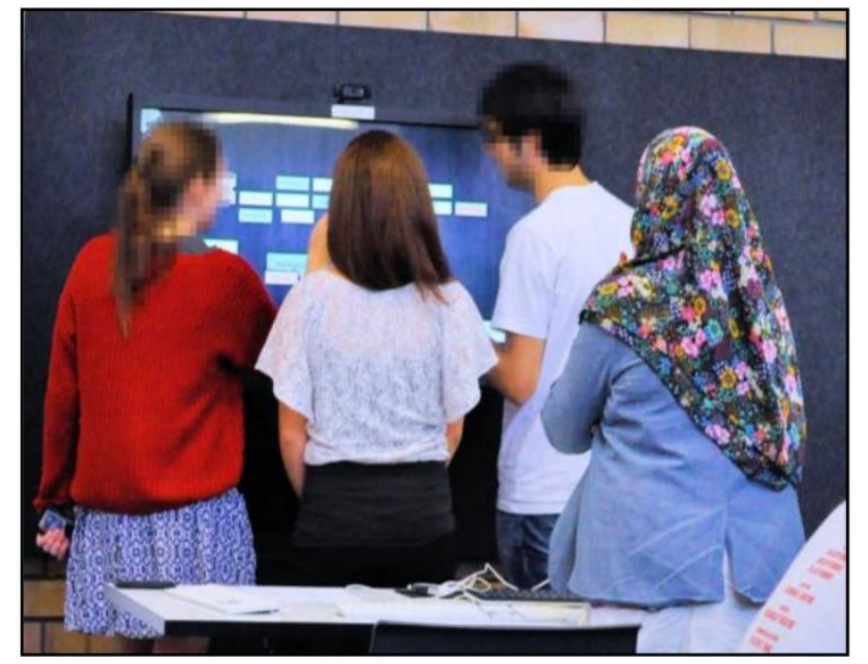

Figure 9: Interaction with the ideas generated at the interactive vertical display - leaving a student behind.

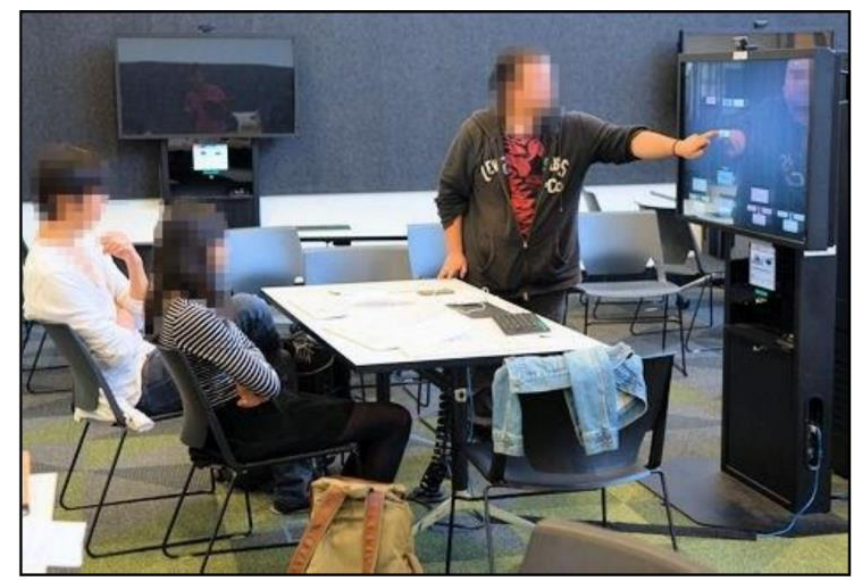

Figure 10: Interaction with the ideas generated at the interactive vertical display - with a conductor.

strategy with a conductor at the display (Figure 10) with all actively participating. We note that a classroom teacher would be able to see these behaviours at a glance around the room; this would provide an opportunity to coach students into better collaboration practices.

\section{Quality of Ideas and Creativity}

The last activity of the day was reflection and sharing. As described earlier, each topic was explored by the teacher, with each group given 30 seconds to pitch their best idea/s (from each topic) to the class (25 mins overall). These were then voted on by the students, producing a ranking of the ideas (5 mins overall). A week after the study, three instructors (the teacher and two tutors) from the subject independently ranked the submitted top ideas. They were given a sheet with the ideas printed on them. The instructors used criteria of originality, innovation and practicality to rank the ideas (equal ranks were allowed). On average (when ranks were clustered), instructors agreed on the same ranking $55 \%$ of the time, whilst students when compared with the teacher-in-charge (the main lecturer) were in- 
agreement $47 \%$ of the time. Instructors gave 28 ideas a top rank ( 8 ideas from topic: 'usb'; 9 from topic: 'lecture slides'; 11 from topic: 'wayfinding'). Across the learning environment conditions, the average numbers of top ranked ideas selected were: 2.3 (tabletop), 3.7 (vertical display) and 3.3 (index cards). With these small numbers, we interpret this as a spread of ideas coming from each condition. The top ideas selected by the teacher in charge were: "USB acts as both a log-in and log-out key/token" (Section B, Group 5 - Index Cards); "A service similar to Facebook timeline that allows you to search items posted during the course of the semester including all material posted by the lecturer" (Section B, Group 3 - Vertical Display); and "Augmented reality - shows you a 3D map that helps users determine location" (Section A, Group 4 - Vertical Display). Overall, there was no relationship between learning environment and creation of top ideas.

To further examine quality, the teacher-in-charge (the main lecturer) and one tutor rated all of the ideas from the day's session (approximately 750 ideas). They used the same criteria for quality (originality, innovation and practicality) but instead this time, used a rating scheme between 1 and 5 ( 5 being best). The measured weighted Cohen's Kappa (squared weights) for the ratings by the two raters was 0.31 (95\% CI: [0.23, 0.39]), indicating a fair agreement (Landis and Koch, 1977). This agreement rating is likely due to the subjective nature of the task, with an inherent difficulty in assessing open ended ideas. The raters were very sparing in awarding scores of 4 and 5 (less than $4 \%$ overall). For this reason, we analysed these scores together as the 'better ideas' from the day's activity. For each learning environment, the average of 4 and 5 scores was 1.08\% (Tabletop), 1.34\% (Vertical Display), and $1.21 \%$ (Index Cards). A Kruskal-Wallis test revealed no significant differences. When the topics were analysed, the majority of high scores came from the USB topic, with an average of 3\%, as opposed to $0.3 \%$ for both of the other two topics. There was no link between topic and learning environment. For example, the 4 and 5 score frequencies for the USB topic were: 6 from the tabletop, 8 from the vertical display and 7 from the index cards.

\section{Discussion}

This section has three parts. The first reflects upon the study design and its impact on the results just reported. Then we consider each of our two research questions in turn, to summarise the key results.

\section{Reflections on the study design, strengths, weaknesses and implications.}

Our study design was within-class-groups and in-the-wild and each of these involved many fine grained study design decisions. Some related to the design of the interfaces and the learning spaces. One of the most important design decisions was the choice of data to collect to answer our research questions. We drew upon a combination of log data, observations and student answers to Likert-scale questions and additional comments. We now discuss the implications of these aspects.

Our within-class-groups study design meant each group practiced each task, experienced each learning environment and tackled each problem, although different groups did them in different orders. This approach, like most of other related work summarised in Tables 1 and 2, is effective for studies involving small numbers of participants, in our case 51 students, in 14 groups across 3 classroom environments. Ideally, the three tasks would have been strictly comparable. In terms of the numbers of ideas generated, summarised in Table 6, this appeared to be the case. However, the rating of all ideas by the lecturer and tutor's assessment gave most for the USB topic, with $3 \%$ compared with $0.3 \%$ for the 
other two topics. This may be a confound for topic comparability or, as discussed below, it may be due to the difficulty of assessing the quality of ideas.

Our commitment to an in-the-wild study was because we believe this contributes to the meaningfulness of the results for real learners in future classrooms that may incorporate SDGs. We now note some of the aspects that contributed to the authenticity of the learning environment. Participants had a clear understanding that they were in a classroom, learning a skill within the curriculum. There was also authenticity in the time constraints: the study had to fit in set class time, with associated time limits. Our choice of brainstorming was to fit within the regular curriculum and its established subject learning objectives. Our conventional class condition was authentic; in fact, it was identical to one of the practice sets of the established tutorial schedule from previous years.

Reflecting on the choice of application, we consider brainstorming was a valuable case to study. It is well suited to SDG support. In terms of generality of our findings, it is a rich collaborative activity, with its divergent idea generation stage and convergent later stages. So, it enabled us to assess diverse aspects of collaboration, both in observations and in light of student comments.

However, the in-the-wild nature of the study imposed limitations. It created time pressures, and we lost data for a part of the idea categorisation phase, as a moving observer for the first brainstorm in the vertical setting failed to do the individual observations. So, this intended analysis had to be omitted. A similar outcome was reported by Kharrufa et al. (2013a), reflecting this risk of 'in-the-wild' classroom studies. Pressures may have also been an explanation for the observation that only the first group in the conventional classroom did any drawing; while all the others simply wrote text. When the team discussed this, we concluded that this may well have been an order effect (with the student experiences at the SDGs encouraging them to continue using only text for the brainstorm on cards). But the teacher also thought that under the time pressure, they may have slipped when giving the instructions to each group, encouraging drawing for the first group only.

We note that with a limited number of observers in our study setup, reliability measures for the stationary and moving observers were not possible. Although all observers were trained on how to code the groups, we are limited to the observations captured, according to our defined coding schemes. In short, this is a trade-off between what students' data we could capture and the constraints imposed by running the collaborative task in a real classroom in-the-wild. Understandably, this limits the interpretation power of these collected aspects.

As described in the study design, we took considerable care with the layout and seating for the learning environment, particularly the vertical condition. While the conventional and tabletop classes lent themselves to students sitting around the table, we had to carefully design the vertical condition. In all conditions, students sat around a table for the idea generation phase and they had more options for the vertical condition convergent stages.

We now consider the potential effects of our brainstorming interfaces, particularly whether the design favoured one condition. We worked hard to avoid this. The interface was carefully designed for each orientation. The tabletop version had been refined over several studies (Clayphan et al., 2011; Clayphan et al. 2014) and an explicit design goal was to make use of the tabletop's potential affordances for users to sit around the table, face-to-face. We also refined and rigorously evaluated support for scaffolding the collaboration. When we translated these results to the vertical condition, we conducted informal testing and refinement of the interface. Our study design also took careful account of this potential confound, with a series of questions asking students to explicitly compare the three settings. Students gave similar 
scores to both the vertical display and tabletop for being able to understand what was required to complete the brainstorm, represent ideas and being able to participate.

Of the dimensions we identified (see Table 4), two of these were specific to brainstorming: the count of ideas and the assessment of the quality of ideas, especially for those identified as best by the students and the teachers. Much of the work on brainstorming reports the first, partly because it is very easy to do but also because large numbers of ideas are claimed to enhance creativity (Osborn, 1953). It is unusual for brainstorming literature to attempt to analyse the quality of the ideas produced (Isaksen, 1998). Our approach was based on three analyses. The first and second were based on the students and 3 teachers' assessment of those ideas the groups had chosen to share as their best. The third analysis involved 2 teachers scoring all ideas generated. In all cases, there was no difference across conditions and only weak agreement between coders. For example, the Kappa agreement between the two teacher's ratings in the third case was only 0.31 . This had the USB case higher than the others by a factor of 10 . If valid, this is unfortunate; we had hoped to see a potential learning effect with the last brainstorm producing better results. But the dominance of the USB topic may have masked that for this analysis. Overall, we put considerable effort into assessing the quality of the brainstorm results, but the results seem to mainly point to the difficulty of doing that.

Lastly, our study was clearly prone to novelty effects, especially for the direct data from the students in the questionnaire. This is because the study was different from the typical classes even for these students. The students moved to 3 different rooms, and used two forms of technology that are not the norm in classrooms. Students were also well aware that they were involved in a study, having been presented with the study description and consent materials a week prior, and they would have been very aware of the presence of our observers. This clearly has implications for authenticity. It is indisputable that tabletops are more novel than vertical displays and both are novel compared the conventional indexcard condition. Even with $35 \%$ reporting prior experience with a tabletop, the novelty effect is likely to have affected student ratings. This has implications for both research questions as we discuss below.

\section{Research Question 1: Do SDGs provide benefits over conventional card-based methods for students learning to brainstorm?}

Briefly, the key results for this research question are that SDG classrooms did provide benefits over the conventional classroom for several key indicators.

- Students created more ideas, a result that is considered important for brainstorming (Osborn, 1953), and is in line with previous work (Clayphan et al., 2011).

- The typed, rather than handwritten ideas, had benefits in terms of sharing as they enhanced readability for all group members, with greater satisfaction at the rate and ease of production. This is also confirmed in Clayphan et al. (2011), Pantidi et al. (2009), and Jaco et al. (2014) who also noted impacts of hand-writing illegibility as a factor affecting collaboration.

- The visibility of all the ideas in the SDG conditions is likely to have helped spark new ideas, a finding supported in literature by Clayphan et al. (2013) and Jaco et al. (2014).

- Every group worked collaboratively in the SDG condition, where the index card classes achieved this in only 5 of 13 cases.

- The SDGs increased students' attention and interest in the activity, although this result is particularly prone to the novelty effect. 
- Students perceived that the SDG classrooms enabled them to participate more; and helped support collaboration.

In contrast to these results, there did not appear to be benefits in terms of:

- The number of top ideas coming more strongly from the SDGs.

- A deviation from the levels of constructing, monitoring and disengagement across all conditions.

\section{Research Question 2: Do tabletops provide better support for students learning to brainstorm in terms of the nature of the collaboration (both observed and perceived) and in the quality of the brainstorm outcomes?}

For this research question, the key differences between the tabletops and interactive walls are only on the measures from the student questionnaires.

- For mutual awareness, the students reported the tabletop was better because it gave better face-to-face interaction.

- Two aspects were close to statistical significance in favour of the tabletop ( $\mathrm{p}=0.056$ for Q1 on ability to represent ideas and $\mathrm{p}=0.087$ for $\mathrm{Q} 9$ on the technology supporting collaboration).

But the tabletops and interactive walls proved to be equally effective on many counts.

- Similar numbers of ideas were created.

- Also similar numbers of top ideas.

- Overall, the observers assessed similar levels of: collaborative work and time spent within each of the participation strategies (constructing, monitoring and disengagement).

This study points to design considerations for creating future classrooms that support small-group collaborative learning activities by incorporating horizontal interactive displays.

- Horizontal displays create a design challenge for readability of all the ideas for all users. We tackled this with an egalitarian layout, with ideas in a circle around the table, making similar numbers of ideas correctly oriented to each user. We intended that this would spur students to move the ideas and talk about them in the convergent phase.

- The position of students around the tabletop favoured egalitarian participation, with all naturally placed to interact with the interface, reducing the risk of students being excluded as we saw in the vertical condition. The recommendation is design for 'egalitarian use' and for devices where orientation cannot be guaranteed 'design for orientation independence'.

- The tabletop, being visible to the teacher only when they are quite close, is likely to reduce teacher awareness of each group in the class (Martinez-Maldonado et al., 2014) (as remarked by the teacher in the tabletop environment). Kharrufa et al. (2013b) provides guidelines for extending single tabletop application design to classrooms and recommend that teachers are provided with group indicators via a private personal channel.

This study highlights particular benefits and considerations for creating future classrooms that support small-group collaborative learning activities that incorporate the use of vertical interactive displays.

- We have demonstrated that, with careful design of the layout, it is possible to utilise learning spaces that enable students to do brainstorming, a complex collaborative task effectively. 
- Students found the vertical orientation facilitated engagement with the ideas of other members of the group.

- The design meant that the first stage of the brainstorm involved seated work for idea generation; this meant that a teacher (and other students) could readily scan around the room to view the progress of each group.

- The entering of ideas via individual keyboards mitigated the need for a complex method for registering and recording ideas. This meant students had a clear view of group contributions (without any of the readability issues encountered at the tabletop).

- A limitation was not all students were able to interact with the surface (when it came time for categorisation and discussion). With limited space for user arrangement in front of the vertical display, this points to likely requiring further task structure and/or scaffolding guidance to ensure students feel supported at the display. A recommendation is 'design activities and spaces together for egalitarian use'.

\section{Conclusions}

We set out to gain insights into whether the use of interactive tables and/or walls could support the activity of small groups engaging in learning to brainstorm, compared with each other and with a conventional method of brainstorming. We undertook this work with an authentic learning activity and in an authentic classroom context, with established subject learning objectives. Our work is novel on several levels. It is the first to:

- compare vertical and horizontal multi-touch displays; previous work involved older pen interaction and mixes of digital and non-digital interaction,

- compare vertical and horizontal displays in an authentic classroom setting,

- compare these with the conventional classroom, and

- $\quad$ conduct the study in an authentic class setting with realistic class-group sizes (3-4).

The chosen task was brainstorming, which is a richly collaborative activity, and leverages on cognitive stimulation, social comparison and group awareness processes. It is also representative of a large class of collaborative activities, with an initial divergent phase, and later convergent discussion phases. Importantly, the chosen activity was part of the teacher's regular course, as in previous sessions. We carefully designed the brainstorming interfaces for each of the horizontal and vertical conditions to make good use of the different affordances of each. The interfaces adapted support for 'interpersonal interaction', 'appropriately arranged users', 'simultaneous user actions' and 'user accountability' (Scott et al., 2003; Kharrufa et al., 2013b). This is in contrast to previous work (Clayphan et al., 2011; Pantidi et al., 2004; Rogers and Lindley, 2004), which exhibited an assortment of design related issues (e.g. devices physically situated far from users, ergonomic problems, and technology imposed sharing limitations). A core contribution of our work was to add to the currently very small body of work on the ways that horizontal and vertical single-display groupware support collaborative activities.

Although no previous work had compared modern multi-touch displays, when we began this work, literature led us to expect that the tabletops would give better support for collaboration in both the ideation and discussion phases than the vertical displays (Clayphan et al., 2011; Rogers and Lindley, 
2004). Our results are particularly important in terms of the promise shown for interactive vertical displays. This may have been due to our careful design of the learning spaces with the interfaces and tuning the application to make effective use of the vertical orientation. Given the demonstrated effectiveness of our vertical display, they seem particular promising for supporting small group work and collaboration. Vertical displays can be placed around the classroom, with desks, wireless keyboards, and other devices moved nearby as needed. They have the merit of orientation familiarity, which can enable user interface designers to draw on established design knowledge. They also offer potential for teachers and learners to see the activity across the class. Moreover, careful design of the physical layout can facilitate some face to face interaction around an accompanying table, as in our classroom.

A core contribution of our work was the set of dimensions identified for studying collaboration around vertical displays and tabletops in the classroom. The first, the number of ideas generated is particularly important for the divergent ideation phase of brainstorming; it may be relevant to the divergent phase of other collaborative activities. The last, the quality of ideas; is important in assessing the outcomes of collaboration, although it is difficult to do, and influenced by a complex set of factors such as each group member's background and motivation. The other dimensions were mutual awareness, which highlighted the intimacy of the tabletop and readability at the vertical displays; participation strategies, which showed how students accounted for technology/material affordances and limitations, level of interest and response to the learning space configuration. We drew upon multiple sources of evidence about these: $\log$ s and the index cards; observations; student questionnaire responses; and expert scoring of the outcomes. This approach is valuable for future studies of surface technologies intended to support collaboration in the classroom.

Our results reinforce the need for the consideration of both the design of the user interface, and the learning task. This study highlighted important affordances offered by different forms of technology that should be considered when creating the learning design. In our case, the technology helped create more ideas, but on quality, the outcome was not as strong as might have been imagined. For this, the learning activity itself appeared to be the main driver. The results also point to the potential benefit of a hybrid setup with both a tabletop and a vertical display, enabling the devices to complement one another, mitigating limitations of either device.

In summary, our work is a key step towards understanding how to make effective use of SDGs for supporting small group work and collaboration in educational contexts and settings.

\section{Acknowledgements}

This work was partially funded by the Smart Services CRC. This research was also supported by funding from the Faculty of Engineering \& Information Technologies, The University of Sydney, under the Faculty Research Cluster Program. The views expressed herein are those of the authors and are not necessarily those of the Faculty. The study presented was conducted with full adherence to the human ethics committee provisions as outlined by the University of Sydney. The ethics protocol used was \#13275. We would like to thank the students for their input, and Oliver Dawson, Xavier Ho and Abeer Mahendroo for their assistance in helping run the study. 


\section{References}

AlAgha, I., Hatch, A., Ma, L., \& Burd, L. (2010). Towards a teacher-centric approach for multitouch surfaces in classrooms. In Proceedings of the International Conference on Interactive Tabletops and Surfaces (ITS 2010). ACM. 187-196

Barkley, E. F., Cross, K. P., \& Major, C. H. (2014). Collaborative learning techniques: A handbook for college faculty: John Wiley \& Sons.

Betcher, C., \& Leicester, M. (2009). The interactive whiteboard revolution: Teaching with IWBs: Australian Countril for Educational Research (ACER) Press.

Binkley, M., Erstad, O., Herman, J., Raizen, S., Ripley, M., Miller-Ricci, M., \& Rumble, M. (2012). Defining twenty-first century skills. In Assessment and teaching of 21st century skills. Springer, 17-66

Chen, W. (2006). Supporting teachers' intervention in collaborative knowledge building. Journal of Network and Computer Applications, 29(2), 200-215.

Clayphan, A., Collins, A., Ackad, C., Kummerfeld, B., \& Kay, J. (2011). Firestorm: A brainstorming application for collaborative group work at tabletops. In Proceedings of the International Conference on Interactive Tabletops and Surfaces 2011 (ITS 2011). ACM. 162-171

Clayphan, A., Martinez-Maldonado, R., \& Kay, J. (2013). Open learner models to support reflection on brainstorming at interactive tabletops. Artificial Intelligence in Education. 683-686

Clayphan, A., Kay, J., \& Weinberger, A. (2014). ScriptStorm: scripting to enhance tabletop brainstorming. Personal and Ubiquitous Computing, 18(6), 1433-1453.

Darling-Hammond, L. (2012). Policy frameworks for new assessments. Assessment and teaching of 21st century skills. Springer, 301-339

Deutsch, M. (1949). An experimental study of the effects of cooperation and competition upon group process. Human relations, 2(3), 199-231.

Dillenbourg, P. (1999). What do you mean by 'collaborative learning'? In Collaborative Learning: Cognitive and Computational Approaches. 1-19

Dillenbourg, P., \& Evans, M. (2011). Interactive tabletops in education. International Journal of Computer-Supported Collaborative Learning, 6(4), 491-514.

Dourish, P., \& Bellotti, V. (1992, December). Awareness and coordination in shared workspaces. In ACM conference on Computer-supported cooperative work. 107-114.

Do-Lenh, S. (2012). Supporting Reflection and Classroom Orchestration with Tangible Tabletops. PhD Dissertation, École Polytechnique Fédérale de Lausanne.

Dugosh, K. L., Paulus, P. B., Roland, E. J., \& Yang, H. C. (2000). Cognitive stimulation in brainstorming. Journal of personality and social psychology, 79(5), 722.

Dugosh, K. L., \& Paulus, P. B. (2005). Cognitive and social comparison processes in brainstorming. Journal of experimental social psychology, 41(3), 313-320.

Evans, M., \& Rick, J. (2014). Supporting Learning with Interactive Surfaces and Spaces. In Handbook of Research on Educational Communications and Technology. Springer. 689-701

Gillies, R. M. (2003). Structuring cooperative group work in classrooms. International Journal of Educational Research, 39(1), 35-49.

Hall, I., \& Higgins, S. (2005). Primary School Students' Perceptions of Interactive Whiteboards. Journal of Computer Assisted Learning, 21(2), 102-117. 
Hatch, A., Higgins, S., \& Mercier, E. (2009). SynergyNet: supporting collaborative learning in an immersive environment. In STELLAR Workshop - Tabletops for Education and Training.

Higgins, S., Beauchamp, G., \& Miller, D. (2007). Reviewing the literature on interactive whiteboards. Learning, Media and Technology, 32(3), 213-225.

Higgins, S., Mercier, E., Burd, L., \& Joyce-Gibbons, A. (2012). Multi-touch tables and collaborative learning. British Journal of Educational Technology, 43(6), 1041-1054.

Inkpen, K., Hawkey, K., Kellar, M., Mandryk, R., Parker, K., Reilly, D., Scott, S., \& Whalen, T. (2005). Exploring display factors that influence co-located collaboration: angle, size, number, and user arrangement. In Proceedings of $\mathrm{HCl}$ international.

Isaksen, S. G. (1998). A review of brainstorming research: Six critical issues for inquiry: Creative Research Unit, Creative Problem Solving Group-Buffalo.

Jaco, A. A., Buisine, S., Barré, J., Aoussat, A., \& Vernier, F. (2014). Trains of thought on the tabletop: visualizing association of ideas improves creativity. Personal and Ubiquitous Computing, 18(5), 1159-1167.

Johnson, D. W., \& Johnson, R. T. (1987). Learning together and alone: Cooperative, competitive, and individualistic learning: Prentice-Hall, Inc.

Kharrufa, A., Balaam, M., Heslop, P., Leat, D., Dolan, P., \& Olivier, P. (2013a). Tables in the Wild: Lessons Learned from a Large-Scale Multi-Tabletop Deployment. In Proceedings of the ACM SIGCHI Conference on Human Factors in Computing Systems (CHI'13). ACM. 1021-1030

Kharrufa, A., Martinez-Maldonado, R., Kay, J., \& Olivier, P. (2013b). Extending tabletop application design to the classroom. In Proceedings of the ACM International Conference on Interactive Tabletops and Surfaces. (ITS 2013). ACM. 115-124.

Koschmann, T. D. (1996). CSCL, theory and practice of an emerging paradigm: Routledge.

Kozlowski, S. W., \& Bell, B. S. (2003). Work groups and teams in organizations. Handbook of psychology.

Kozlowski, S. W., \& Ilgen, D. R. (2006). Enhancing the effectiveness of work groups and teams. Psychological science in the public interest, 7(3), 77-124.

Landis, J. R., \& Koch, G. G. (1977). The measurement of observer agreement for categorical data. biometrics, 33(1), 159-174.

Martinez-Maldonado, R., Clayphan, A., Ackad, C., \& Kay, J. (2014). Multi-touch technology in a higher-education classroom: lessons in-the-wild. In Proceedings of the Australian Computer-Human Interaction Conference. (OzCHI 2014). ACM. 220-229

Martinez-Maldonado, R., Collins, A., Kay, J., \& Yacef, K. (2011). Who did what? who said that? Collaid: an environment for capturing traces of collaborative learning at the tabletop. In Proceedings of the International Conference on Interactive Tabletops and Surfaces (ITS 2011). ACM. 172-181

Martinez-Maldonado, R., Kay, J., Yacef, K., Edbauer, M.-T., \& Dimitriadis, Y. (2012a).

Orchestrating a Multi-tabletop Classroom: from Activity Design to Enactment and Reflection. In Proceedings of the ACM International Conference on Interactive Tabletops and Surfaces (ITS 2012). ACM 119-128

Martinez-Maldonado, R., Yacef, K., Kay, J., \& Schwendimann, B. (2012b). Unpacking traces of collaboration from multimodal data of collaborative concept mapping at a tabletop. In Proceedings of the International Conference of the Learning Sciences (ICLS 2012). ISLS. 241-245 
Mercer, N., Warwick, P., Kershner, R., \& Staarman, J. K. (2010). Can the interactive whiteboard help to provide 'dialogic space' for children's collaborative activity? Language and education, 24(5), 367-384.

Mercier, E., Higgins, S., Burd, E., \& Joyce-Gibbons, A. (2012). Multi-Touch Technology to Support Multiple Levels of Collaborative Learning in the Classroom. In Proceedings of the International Conference of the Learning Sciences (ICLS 2012). ISLS. 187-191

Mercier, E. M., \& Higgins, S. E. (2013). Collaborative learning with multi-touch technology: Developing adaptive expertise. Learning and Instruction, 25, 13-23.

Morris, M. R. (2006). Supporting effective interaction with tabletop groupware. In Horizontal Interactive Human-Computer Systems, TableTop 2006. IEEE 56-58.

Muir-Herzig, R. G. (2004). Technology and its impact in the classroom.Computers \& Education, 42(2), 111-131.

Müller-Tomfelde, C., \& Fjeld, M. (2012). Tabletops: Interactive Horizontal Displays for Ubiquitous Computing. Computer, IEEE. 78-81.

Murcia, K., \& Sheffield, R. (2010). Talking about Science in Interactive Whiteboard Classrooms. Australasian Journal of Educational Technology, 26(4).

OECD. (2011). OECD Guide to Measuring the Information Society 2011: Organisation for Economic Co-operation and Development.

OECD. (2013). PISA 2015 Draft Collaborative Problem Solving Framework: Organisation for Economic Co-operation and Development.

Osborn, A. F. (1953). Applied Imagination: Principles and Procedures of Creative Problem Solving. New York: Charles Scribener's Sons.

Pantidi, N., Rogers, Y., \& Robinson, H. (2009). Is the Writing on the Wall for Tabletops? In Human-Computer Interaction (INTERACT 2009). Springer. 125.137

Paulus, P. (2000). Groups, Teams, and Creativity: The Creative Potential of Idea-generating Groups. Applied psychology, 49(2), 237-262.

Piper, A. M., Friedman, W., \& Hollan, J. D. (2012). Setting the stage for embodied activity: scientific discussion around a multitouch tabletop display. International Journal of Learning Technology, 7(1), 58-78.

Piper, A. M., \& Hollan, J. D. (2009). Tabletop displays for small group study: affordances of paper and digital materials. Proceedings of the SIGCHI Conference on Human Factors in Computing Systems.

Potvin, B., Swindells, C., Tory, M., \& Storey, M. A. (2012). Comparing horizontal and vertical surfaces for a collaborative design task. Advances in Human-Computer Interaction, 2012, 6 .

Rick, J., Marshall, P., \& Yuill, N. (2011). Beyond one-size-fits-all: How interactive tabletops support collaborative learning. In Proceedings of the 10th International Conference on Interaction Design and Children. ACM 109-117

Rogers, Y., \& Lindley, S. (2004). Collaborating around vertical and horizontal large interactive displays: which way is best? Interacting with Computers, 16(6), 1133-1152.

Salas, E., Cooke, N. J., \& Rosen, M. A. (2008). On teams, teamwork, and team performance: Discoveries and developments. Human Factors: The Journal of the Human Factors and Ergonomics Society, 50(3), 540-547.

Salter, D., Thomson, D. L., Fox, B., \& Lam, J. (2013). Use and evaluation of a technology-rich experimental collaborative classroom. Higher Education Research \& Development, 32(5), 805-819. 
Scott, S. D., Grant, K. D., \& Mandryk, R. L. (2003, January). System guidelines for co-located, collaborative work on a tabletop display. In ECSCW 2003 (pp. 159-178). Springer Netherlands.

Shi, Y., Yang, Z., Yang, H. H., \& Liu, S. (2012). The impact of interactive whiteboards on education. In Proceedings of the International Conference on Internet Multimedia Computing and Service. ACM. 213-218

Slotta, J. D. "Evolving the classrooms of the future: The interplay of pedagogy, technology and community." Classroom of the future: Orchestrating collaborative spaces (2010): 215242.

Smith, H. J., Higgins, S., Wall, K., \& Miller, J. (2005). Interactive whiteboards: boon or bandwagon? A critical review of the literature. Journal of Computer Assisted Learning, 21(2), 91-101.

Springer, L., Stanne, M. E., \& Donovan, S. S. (1999). Effects of small-group learning on undergraduates in science, mathematics, engineering, and technology: A metaanalysis. Review of educational research, 69(1), 21-51.

Stahl, G., Koschmann, T., \& Suthers, D. (2006). Computer-supported collaborative learning: An historical perspective. Cambridge handbook of the learning sciences, 409-426.

Stockert, R., Bjorkli, K., \& Stav, J. (2012). Experiences with Design and Use of Large Collaborative Work and Learning Spaces in Digital Learning Labs. In Proceedings of the EDULEARN12.

Sweeney, T. (2010). Transforming Pedagogy through Interactive Whiteboards: Using Activity Theory to Understand Tensions in Practice. Australian Educational Computing, 24(2), 28-34.

Technologies, SMART. (2006). Interactive Whiteboards and Learning. Improving student learning outcomes and streamlining lesson planning.

Yañez, L., \& Coyle, Y. (2011). Children's Perceptions of Learning with an Interactive Whiteboard. ELT Journal, 65(4), 446-457 